\title{
Bases generales sobre autorización de centros, servicios y establecimientos sanitarios
}

\author{
Juan Francisco Pérez Gálvez \\ Catedrático de Derecho Administrativo \\ Universidad de Almería
}

SUMARIO: I. JUSTIFICACIÓN DE ESTE TRABAJO. II. POTESTAD REGLAMENTARIA Y CONFLUENCIA COMPETENCIAL. 1. Cuestiones formales y materiales de la potestad reglamentaria. 2. Naturaleza de la relación existente entre el ordenamiento estatal y los distintos ordenamientos de las Comunidades Autónomas. 3. Las competencias sobre los centros, servicios y establecimientos sanitarios: "bases-desarrollo". III. EL CONCEPTO DE CENTRO, SERVICIO O ESTABLECIMIENTO SANITARIO Y SU DEPURACIÓN JURISPRUDENCIAL. 1. Centro sanitario. 2. Delimitación respecto a figuras afines. 2.1. El "servicio sanitario" o "unidad asistencial" como objeto de controversia jurídica. 2.2. Establecimiento sanitario. 2.3. Actividad sanitaria. IV. LAS CLASES DE CENTROS, SERVICIOS O ESTABLECIMIENTOS SANITARIOS Y SU RELAGIÓN GON LA GARANTÍA GONSTITUGIONAL DEL EJERCICIO DE LAS PROFESIONES SANITARIAS TITULADAS. V. LA RAZÓN DE INTERÉS GENERAL EN EL DERECHO DE LA UNIÓN EUROPEA [SENTENCIA DEL TRIBUNAL DE JUSTICIA DE LAS COMUNIDADES EUROPEAS (GRAN SALA) DE 10 DE MARZO DE 2009]. 1. Status quaestionis. 2. Litigios principales y cuestiones prejudiciales. 3. Petición de autorización de un centro o establecimiento sanitario y libre prestación de servicios. 3.1. Un supuesto de interés: sentencia del Tribunal de Justicia (Gran Sala) de 1 de junio de 2010. 3.2. Autorización condicionada a la prestación ofrecida por los medios concertados.

\section{RESUMEN}

El Real Decreto 1277/2003, de 10 de octubre, del Ministerio de Sanidad y Consumo, por el que se establecen las bases generales sobre autorización de centros, servicios y establecimientos sanitarios, cumplirá diez años en el ejercicio que acabamos de comenzar. Se trata de una disposición reglamentaria de 
extraordinaria relevancia. Y efectuó esta afirmación, porque no es el dispositivo asistencial el principal condicionante de nuestro nivel de salud, pero su importancia e incidencia están fuera de toda duda.

El estudio y análisis del régimen jurídico y de las controversias dirimidas por nuestros juzgados y tribunales en este sector, configuran el complemento perfecto para valorar la idoneidad de una norma, que de un modo silencioso, otorga carta de naturaleza a la seguridad jurídica que los ciudadanos demandamos en la recepción de estos servicios.

Palabras Clave: Autorización, centros, servicios y establecimientos sanitarios.

ABSTRACT:

The Royal Decree 1277/2003, of 10 October, the Ministry of Health, by laying down the general rules on authorization centers, services and establishments, will be ten years in the year just begun. This is a statutory provision of extraordinary importance in the legal health. And made this statement because no assistive device is the main determinant of our health status, but its relevance and impact, are beyond doubt.

The study and analysis of legal disputes settled by our courts form the perfect complement to assess the suitability of a provision that in a silent, naturalization papers gives legal certainty that citizens demand in receiving these services.

Key Words: Authorization, centers, services and establishments.

\section{JUSTIFICACIÓN DE ESTE TRABAJO}

La sanidad está de moda, o al menos, los temas relacionados con la salud son objeto de consideración en la comunidad científica, los medios de comunicación y en la realidad más cercana. La suspensión cautelar del "euro por receta", la colegiación obligatoria de los empleados públicos, cuando ejercen la profesión por cuenta de la Administración (STC 3/2013, de 13 de enero), la supresión de servicios sanitarios con la pretensión de hacer el sistema más eficiente, las distintas modalidades de gestión o "privatización de la sanidad pública" como aparece referenciada en las cabeceras de la prensa escrita, y un largo etcétera de materias vinculadas de modo directo o indirecto con una prestación muy apreciada y muy bien valorada por los ciudadanos, a tenor de 
los resultados de las encuestas que los centros de investigaciones sociológicas realizan periódicamente, son objeto de atención preferente.

También debo destacar que estamos de aniversario, pues conmemoramos diez años de vida de varios textos legales que inciden notablemente en la articulación jurídica del sector. Entre ellos debo destacar, al menos, los siguientes: Ley 16/2003, de 28 de mayo, de Cohesión y Calidad del Sistema Nacional de Salud, Ley 44/2003, de 21 de noviembre, de Ordenación de las Profesiones Sanitarias y Ley 55/2003, de 16 de diciembre, del Estatuto Marco del Personal Estatutario de los Servicios de Salud. Sin duda, todas ellas serán objeto de tratamiento y consideración pormenorizada, por su relevancia, por su incidencia y por el carácter estructural que tienen en nuestro Sistema Nacional de Salud.

Forma parte de este nutrido grupo de disposiciones, y en la que concurre también la trascendencia y el aniversario referido en el párrafo anterior, el Real Decreto 1277/2003, de 10 de octubre, del Ministerio de Sanidad y Consumo, por el que se establecen las bases generales sobre autorización de centros, servicios y establecimientos sanitarios (BOE de 23 de octubre, núm. 254). Su rango jerárquico puede llevarnos a olvidar su trascendencia, a pesar, de que casi todos los titulares del sector salud que copan los medios de comunicación tienen como base o soporte un centro, servicio o establecimiento sanitario. Debemos tener en cuenta que tal y como determina su disposición final primera: «Este real decreto tiene carácter de norma básica en virtud de lo establecido en el artículo 149.1.16 a de la Constitución». Esta disposición tiene continuidad natural en los respectivos Decretos autonómicos que materializan las bases más desarrollo, propias del esquema de un Estado autonómico como el nuestro.

El estudio de las nuevas disposiciones que se publican en el Boletín Oficial del Estado, forma parte del cometido de los administrativistas. Es frecuente, que incluso antes de su entrada en vigor, comencemos el análisis de las consecuencias que se derivarán de cualquier texto legal. Es menos frecuente, evaluar estas disposiciones a la luz de los problemas reales que su publicación propicia. Dicho de otro modo, no solemos realizar un estudio que permita determinar que cuestiones polémicas ha suscitado la entrada en vigor de una determinada disposición de un modo global. Y para ello, existe un baremo o termómetro perfecto, a saber, la jurisprudencia. Cuando me refiero a la jurisprudencia, no me refiero sólo a «la doctrina que de modo reiterado establece el Tribunal Supremo al interpretar y aplicar la ley, la costumbre y los principios generales del derecho», sino que englobo las sentencias del Tribunal de Justicia de la Unión 
Europea, Audiencia Nacional y también los Tribunales Superiores de Justicia, puesto que los centros, servicios y establecimientos sanitarios, en buena medida, se regulan a través de disposiciones autonómicas.

Por todo lo expuesto, en este trabajo abordaré el régimen jurídico de las bases generales de una realidad, que a pesar de sus múltiples manifestaciones, nos puede pasar desapercibida.

\section{POTESTAD REGLAMENTARIA Y GONFLUENGIA COMPE- TENCIAL}

\section{Cuestiones formales y materiales de la potestad reglamentaria.}

Tanto la Ley General de Sanidad (art. 29.2) como la Ley de Cohesión y Calidad del Sistema Nacional de Salud (Disposición Final 5a), básicas en la materia, autorizan al Gobierno para dictar las disposiciones complementarias que sean precisas sobre calificación, registro y autorización de centros, servicios y establecimientos sanitarios. Ese es el objeto fundamental del RD 1277/03, y que desde luego no constituye materia idónea para ser reglada mediante Ley formal ${ }^{1}$.

La titularidad y competencia de la potestad reglamentaria ${ }^{2}$ constituyen exigencias y límites formales del reglamento. Además deberá respetarse el principio de jerarquía normativa respecto a la Constitución y a la Ley (arts. 9.33, 97 y $103 \mathrm{CE}$ ), así como respecto a los demás reglamentos dependiendo de su rango jerárquico. Así lo ha establecido, entre otras, la STSJ de Madrid, de 10 de julio de 2007 (Ar. 801), FD TERCERO:

\footnotetext{
${ }^{1}$ Vide STS de 14 de mayo de 2007 (Ar. 5849), FD SÉPTIMO.

2 Vide SAN de 26 de septiembre de 2007 (Ar. 664), FD TERCERO.

${ }^{3}$ Vide STC 83/1984, donde en relación al principio de legalidad afirma: «Este principio de reserva de Ley entraña [...] una garantía esencial de nuestro Estado de Derecho [...]. Su significado último es el de asegurar que la regulación de los ámbitos de libertad que corresponden a los ciudadanos dependa exclusivamente de la voluntad de sus representantes, por lo que tales ámbitos han de quedar exentos de la acción del ejecutivo y, en consecuencia, de sus productos normativos propios, que son los reglamentos. El principio no excluye, ciertamente, la posibilidad de que las leyes contengan remisiones a normas reglamentarias, pero si que tales remisiones hagan posible una regulación independiente y no claramente subordinada a la ley, lo que supondría una degradación de la reserva formulada por la Constitución a favor del legislador».
} 
«La alegación esencial que vertebra la demanda, bajo la invocación del principio de jerarquía normativa es la de que no puede establecerse en el Decreto impugnado la obligación de llevar hojas de reclamaciones en el ámbito de la sanidad privada hasta que la Comunidad de Madrid - por imponerlo así el art. 26.5 de la Ley 12/2001, de Ordenación Sanitaria de la Comunidad de Madrid- no dicte una norma que regule, específicamente, el sistema de reclamaciones en el ámbito sanitario privado, al igual que lo ha hecho en el ámbito sanitario público mediante la correspondiente Orden de la Consejería de Sanidad (Orden 605/2003), ya que, mientras esa regulación específica del sistema de reclamaciones en el ámbito sanitario privado no se dicte, la imposición de llevar hojas de reclamaciones que establece el precepto impugnado supone la aplicación, en este ámbito, de la legislación general de consumidores, legislación que no se considera de aplicación por el Colegio demandante, en la medida en que las consultas de odontoestomatología se rigen por su normativa propia en la que no se establece dicha obligación.

Y este planteamiento esencial sobre el que se articula la demanda no puede ser aceptado porque la validez de una norma reglamentaria, desde la perspectiva de su respeto a la Ley (principio de jerarquía normativa), no puede depender de que se haya dictado o no una norma que, a su vez, desarrolla la norma reglamentaria que se analiza, que es lo que realmente pretende la parte actora al entender que debió dictarse por la Comunidad de Madrid, en el ámbito de la sanidad privada, una norma similar a la Orden 605/2003, que regula el sistema de reclamaciones en el ámbito de la sanidad pública, antes de dictarse el precepto impugnado que impone la obligación de llevar hojas de reclamaciones también en el ámbito de la sanidad privada.

En efecto, en el presente caso, ninguna vulneración del principio de jerarquía normativa se ha producido por la regulación contenida en el precepto impugnado (art. 21.e del Decreto 51/2006), cuyo contenido no es sino concreción o desarrollo del precepto legal en que con toda naturalidad se inserta el art. 26.5 de la Ley 12/2001, de Ordenación Sanitaria de la Comunidad de Madrid».

La inderogabilidad singular de los reglamentos y el cumplimiento del procedimiento de elaboración de los mismos también forman parte de esa reserva o límite formal al que me he referido. 
Exigencias materiales que afectan al contenido de la norma reglamentaria son la reserva de ley, material y formal, y el respeto a los principios generales del Derecho. Un Derecho que no se reduce al expresado en la Ley, sino que comprende dichos principios en su doble función legitimadora y de integración del ordenamiento jurídico como principios técnicos y objetivos que expresan las ideas básicas de la comunidad y que inspiran dicho ordenamiento. Para cumplir esta finalidad, es necesario un proceso en su elaboración que garantice la participación de todos aquellos que ostentan la condición de interesados. De este modo, el trámite de audiencia, constituye un elemento esencial del mismo, en los términos que han sido determinados por la STS de 5 de julio de 2005 (Ar. 5206), FD PRIMERO:

«En segundo lugar y por lo que se refiere a la exigencia legal del trámite de audiencia en la elaboración de disposiciones generales, el 105, apartado a) de la Constitución, establece que: "la Ley regulará la audiencia de los ciudadanos, directamente o a través de las organizaciones y asociaciones reconocidas por la Ley, en el procedimiento de elaboración de las disposiciones administrativas que les afecten", precepto desarrollado en el artículo 24.1.c) de la Ley 50/1997, de 27 de noviembre, de Organización, Competencia y Funcionamiento del Gobierno, según el cual: "elaborado el texto de una disposición que afecte a los derechos e intereses legamitos de los ciudadanos, se les dará audiencia durante un plazo razonable y no inferior a quince días hábiles, directamente o a través de las organizaciones y asociaciones reconocidas por la Ley que los agrupen o los representen y cuyos fines guarden relación directa con el objeto de la disposición".

En cuanto al alcance de tal previsión legal, esta Sala ha declarado en las sentencias de [...], que el trámite de audiencia ha de calificarse como participación funcional en la elaboración de disposiciones de carácter general "preceptivamente impuesta" y que "requiere en el órgano que instruye una actividad configurada técnicamente como carga, concretada en la llamada de las organizaciones y asociaciones que necesariamente deben ser convocadas pues, en otro caso, el procedimiento podría quedar viciado o incluso la disposición resultante podría estar incursa en nulidad", debiendo distinguir que la audiencia es preceptiva para Asociaciones que no sean de carácter voluntario, pero no cuando se trata, de asociaciones voluntarias de naturaleza privada, que, aunque estén reconocidas por la Ley, no ostentan "por Ley" la representación a que aquel precepto se refiere, pues es este criterio el que traduce con mayor fidelidad el ámbito subjetivo de aquel precepto. [...]. 
Pues bien, desde estas consideraciones generales, lo primero que se advierte en este caso, es que en la elaboración del Real Decreto 1277/2003 impugnado, no sólo se ha dado trámite de audiencia a las organizaciones y asociaciones que necesariamente debían ser emplazadas al efecto sino que se ha incluido la audiencia de un considerable número de asociaciones de carácter voluntario, [...], habiéndose oído igualmente a las Comunidades Autónomas, a pesar de no contemplarse específicamente tal exigencia, como expresamente se indicaba en el informe de la Secretaría General Técnica del Ministerio de Justicia [...], por lo que objetivamente no se advierte la infracción de los indicados preceptos, al haberse cumplido ampliamente con dicho trámite» ${ }^{4}$.

Teniendo presente en todo caso, que la preceptividad de la audiencia excluye las asociaciones de carácter voluntario, aunque nada impide que dicha audiencia pueda ser llevada a cabo si este procedimiento aparece como adecuado en función de las circunstancias, pudiendo incluso recabar el informe de entidades de afiliación voluntaria que agrupen a colectivos afectados ${ }^{5}$.

\section{Naturaleza de la relación existente entre el ordenamiento es- tatal y los distintos ordenamientos de las Comunidades Autó- nomas.}

La nueva ordenación territorial del Estado que introdujo la Constitución Española de 1978 en su Título VIII ha supuesto un cambio radical en las relaciones entre los diferentes ordenamientos jurídicos.

Esta ordenación territorial, con independencia de la integración del Derecho Comunitario Europeo, se establece en tres niveles - Administración del Estado, Administración de las Comunidades Autónomas y Administración Local- sobre la base del principio de autonomía (art. 137 CE), que implica una potestad normativa propia, base de otros tantos ordenamientos singulares en relación con el ordenamiento general del Estado.

Esta pluralidad normativa, derivada de centros organizativos separados, se configura constitucionalmente sobre la base de tres principios generales (sigo

\footnotetext{
${ }^{4}$ En idénticos términos Vide STS de 1 de diciembre de 2008 (Ar. 200).

${ }^{5}$ Vide STS de 14 de mayo de 2007 (Ar. 5849), FD OCTAVO.
} 
aquí la argumentación de la STS de 13 de octubre de 2003, Ar. 7917, ponente: Fernández Montalvo):

a) Las Comunidades Autónomas han supuesto un cambio sustantivo respecto de la naturaleza de los entes locales. Estos son entes con poderes esencialmente administrativos, cuya competencia normativa, aunque opere en un ámbito autonómico garantizado por la Ley (Leyes de Régimen Local o leyes sectoriales) y esté cubierta por una "garantía institucional" en la propia Constitución, es meramente reglamentaria.

Por el contrario, las Comunidades Autónomas no son simples entes administrativos, sino que poseen una verdadera esencia política por su misma posición constitucional y cuentan con un conjunto de poderes y funciones en un Estado que el Tribunal Constitucional ha calificado de "Estado compuesto", aludiendo al sistema de autonomías político-territoriales de nacionalidades y regiones que consagra, como uno los principios básicos, el artículo 2 CE.

Las Comunidades Autónomas tienen genuinos poderes legislativos. Y, por su parte, el Tribunal Constitucional ha considerado que las leyes autonómicas pueden cubrir por sí mismas la reserva constitucional de Ley, con lo que se establece la identidad de naturaleza con la ley ordinaria del Estado. La Ley del Estado y la Ley autonómica tienen, pues, el mismo rango y valor en sus respectivos ámbitos de competencia.

b) Las complejas relaciones internormativas que se producen no pueden explicarse sobre el principio de jerarquía. Aparece, por el contrario, un principio esencial de relación internormativa, cual es el principio de competencia.

Las normas autonómicas surgen en ámbitos competenciales reservados a favor de la respectiva Comunidad Autónoma por la Constitución y los Estatutos (arts. 143 y 147) por las leyes orgánicas de transferencia o delegación de facultades (art. 150.2) y por las leyes marco (art. 150.1 y 3). Dentro de esos ámbitos de autonomía las leyes y reglamentos del Estado no están supraordenados a las normas autonómicas antes bien están excluidos, por virtud de la reserva constitucional o legal.

La pluralidad de ordenamientos implica que cada uno tenga un ámbito propio; de manera que una norma de Comunidad Autónoma que penetrase en el ámbito estatal o viceversa, sería nula por vulneración de las normas constitucional y estatutaria que han construido tal ámbito competencial. 
El principio de separación de los ordenamientos se instrumenta de forma recíproca ante el Tribunal Constitucional, bien mediante el recurso o cuestión de inconstitucionalidad, bien mediante el conflicto de competencias entre el Estado y las Comunidades Autónomas, sin perjuicio de la garantía judicial ordinaria que presta la jurisdicción contencioso-administrativa.

c) La indicada relación de los ordenamientos estatal y autonómico se producen sin perjuicio de la articulación de todos ellos en el supraordenamiento constitucional. La separación entre ordenamientos a que me he referido no es en manera alguna absoluta, sino que encuentra una articulación superior en la Constitución como norma fundamental o norma normarun. Así pues, la unidad del ordenamiento general del Estado se encuentra en el nivel constitucional que comprende y abarca la totalidad de los dos subsistemas: el estatal stricto sensu y los autonómicos.

De esta posición de cada ordenamiento con la Constitución, en cuanto tronco común de todos ellos, deriva:

$\left.1^{\circ}\right)$ Si bien existe separación entre las dos clases de ordenamiento, estatal y autonómico, las relaciones respectivas de cada uno de ellos con la Constitución es de subordinación jerárquica.

$\left.2^{\circ}\right)$ La validez de todas las normas, tanto del Estado como de los ordenamientos autonómicos, está condicionada a su constitucionalidad.

$3^{\circ}$ ) No sólo el Derecho estatal, sino la totalidad de los Derechos autonómicos, comenzando por los Estatutos, deben ser interpretados "conforme a la Constitución".

d) A pesar de que la relación entre el ordenamiento estatal y los ordenamientos regionales se rija fundamentalmente por el principio de competencia, no constituyen, sin embargo, compartimentos estancos, en cuanto coinciden en un ámbito personal y territorial de aplicación, y existe una indudable interconexión en la vida social que determina que cualquier actuación administrativa pueda incidir en títulos competenciales diversos atribuidos al Estado y a las Comunidades Autónomas.

Muy gráficamente lo ha expuesto la STSJ de Andalucía, Granada, de 21 de junio de 2010 (Ar. 356131), FD QUINTO:

«Con todo ello puede determinarse que la relación existente entre las normas básicas estatales y las normas de desarrollo de las corres- 
pondientes Comunidades Autónomas se manifiesta en la imagen gráfica de tres círculos concéntricos:

- el primero y central: determinaciones de interés general, común denominador para todos, con efecto preclusivo o de cierre por ser imposible su modificación por el derecho de las Comunidades Autónomas y de desplazamiento respecto de derecho autonómico que pudiera estar hasta entonces regulando la materia.

- el segundo: círculo de encuadramiento, en el que se incluyen todos los aspectos que quedan abiertos a la regulación de las Comunidades Autónomas a efectos de desarrollo de sus propias políticas.

- el tercero: círculo de suplencia, en que la normativa básica se aplicará en las Comunidades Autónomas que no regulen la materia en tanto no dicten normas propias.

Con esta base doctrinal, ha de determinarse que el legislador estatal establece una serie de pautas (la clasificación general de centros, servicios y establecimientos sanitarios) encomendando a las Comunidades Autónomas el desarrollo de esta materia, y también la ejecución de la misma. O sea, que existe una habilitación o mandato legal, ya que no agota el contenido y alcance de la materia regulada en el propio texto legal, sino que se remite a lo que cada Comunidad Autónoma (dentro de su autonomía política) puedan determinar con amplitud de criterio, dejando abierta la posibilidad a que éstas puedan, según sus peculiaridades propias, ampliar la clasificación básica estatal.

Además, esta regulación garantiza el derecho de los ciudadanos, porque somete a autorización administrativa el funcionamiento de otros establecimientos que procedan a la adaptación individualizada de productos sanitarios, descripción que deberá concretar la propia normativa reguladora de los mismos».

\section{Las competencias sobre los centros, servicios y establecimien- tos sanitarios: "bases-desarrollo".}

La Constitución Española de 1978, en su art. 149.1.16 otorga el Estado la competencia exclusiva en materia de "Bases y coordinación general de la sanidad", y el art. 148.1.21 reconoce la posibilidad de que las Comunidades Autó- 
nomas, a través de sus Estatutos de Autonomía, asuman competencias en materia de "Sanidad e higiene". Esta distribución posibilita que Estado y Comunidad Autónoma regulen de modo global este ámbito jurídico. Al primero le corresponde establecer el régimen jurídico básico, y a la segunda, establecer la normativa de desarrollo. Las consecuencias son las siguientes ${ }^{6}$ :

a) La atribución al Estado del establecimiento del mínimo común normativo o la regulación principal uniforme que debe existir y aplicarse con carácter general en todo el territorio nacional. De este modo se asegura un común denominador normativo, a partir del cual cada Comunidad puede establecer las propias peculiaridades.

b) Las bases, que tienen según el Tribunal Constitucional un carácter material o sustantivo, en materia de sanidad comprende, como manifestación esencial y característica, la elección del propio modelo sanitario atribuido, sin duda, al Estado. Y a partir de tal opción la legislación estatal, en defensa del interés general, diseña el fundamento propio de las bases con un contenido circunstancial y variable y los consiguientes efectos de preclusión o de desplazamiento para la normativa autonómica, sin perjuicio, claro está, del ulterior y eventual control del Tribunal Constitucional.

La STSJ de Madrid, de 10 de julio de 2007 (Ar. 801), FD CUARTO, advierte claramente sobre esta cuestión al afirmar:

«[...] en este caso ya no podemos acudir al principio de jerarquía, sino al principio de competencia que es el que articula las relaciones entre las normas estatales y autonómicas. [...].

Como claramente puede colegirse de esta explicación, las normas que se contienen en el citado Real Decreto que afectan al "contenido funcional de las profesiones (de odontólogo, protésico dental e higienista dental) vinculadas a los correspondientes títulos académicos habilitantes" y que regulan, por tanto, "dichas profesiones, así como sus cometidos principales, capacidades y responsabilidades", se han dictado por el Estado al amparo del título competencial previsto en el art. 149.1.30 CE, que atribuye al Estado la competencia sobre la "regulación de las condiciones de obtención, expedición y homologación de títulos académicos y profesionales y normas básicas para el desa-

${ }^{6}$ Vide STS de 13 de octubre de 2003 (Ar. 7917), FD QUINTO. 
rrollo del art. 27 de la Constitución, a fin de garantizar el cumplimiento de las obligaciones de los poderes públicos en esta materia". $\mathrm{Y}$ en cambio, las normas contenidas en dicho Real Decreto que afectan a "los requisitos básicos y mínimos correspondiente a los centros, servicios y establecimientos de salud dental", se han dictado por el Estado al amparo del título competencial previsto en el art. 149.1.16 $\mathrm{CE}$, que atribuye al Estado la competencia, entre otras materias, sobre las "bases y coordinación general de la sanidad".

En este caso, la cuestión discutida -obligación de tener hojas de reclamaciones en los servicios, centros y establecimientos sanitarios públicos y privados, incluidos los de salud dental- afecta a los requisitos de funcionamiento de dichos servicios y establecimientos sanitarios por lo que el título competencial que debemos aplicar es el de "bases y coordinación general de la sanidad", estableciendo en el art. 149.1.16 CE, en cuya virtud, corresponde al Estado en esta materia la legislación básica y a las Comunidades Autónomas el desarrollo de esas bases, $[\ldots]$.

Por tanto, nada tiene de extraño que el citado Real Decreto no establezca la obligación de llevar hojas de reclamaciones en los centros y establecimientos relativos a la salud dental y que esta obligación se imponga, "ex novo", en la legislación autonómica que venimos analizando ya que el concepto material de "bases" impide que la legislación del Estado agote la materia a la que las bases se refieren, pues el desarrollo autonómico de las bases debe permitir a las Comunidades Autónomas llevar a cabo sus propias políticas en la materia, siempre dentro de aquellas bases. Así pues, las bases estatales deben respetar un ámbito de actuación propia de las Comunidades Autónomas, pues la autonomía significa la posibilidad de seguir políticas propias, de forma que siempre ha de quedar un margen de decisión a las Comunidades Autónomas para el desarrollo, como consideren oportuno, de las bases estatales. Y así, como tempranamente señaló el Tribunal Constitucional, "el establecimiento por parte del Estado de las bases de la ordenación no puede llegar a tal grado de desarrollo que deje vacías de contenido las correlativas competencias de la Comunidad.

En consecuencia, ninguna discordancia con el ordenamiento jurídico puede extraerse del hecho, puesto de relieve en la demanda, de que el RD 1594/1994, no establezca esta obligación y si se imponga 
dicha obligación en la norma reglamentaria autonómica analizada, pues se trata, simplemente, del juego normal de la técnica competencial "bases-desarrollo"».

c) El propio mecanismo de bases más desarrollo y aludidos efectos de preclusión y desplazamiento en la determinación de lo básico de una materia, además del efecto de suplencia, determina que las Comunidades Autónomas no tengan supeditado el ejercicio de su competencia normativa de desarrollo a que el Estado dicte la norma básica. Si el legislador no ha definido las bases de una materia, ello no significa que no existen, ni tampoco que el legislador comunitario autonómico no pueda legislar hasta que el estatal las defina ${ }^{7}$.

La STS de 6 de julio de 2005 (Ar. 9541), en un caso donde se cuestiona el carácter básico del RD 1277/2003, de 10 de octubre, por el que se establecen las bases generales sobre autorización de centros, servicios y establecimientos sanitarios, afirma (FD PRIMERO):

«[...]. Tampoco puede llegar a comprender esta Sala a que tipo de doctrina constitucional se refiera la actora cuando alega que ésta no reconoce que se pretenda dotar de carácter de normativa básica en la materia que regula el Real Decreto cuestionado. Ciertamente que el argumento se formula en términos absolutamente genéricos, sin descender con el debido detalle al caso que nos ocupa; pero, de todas formas, lo cierto es que la doctrina constitucional y la jurisprudencia de esta Sala han reconocido en muchas ocasiones el carácter básico - a los efectos del artículo 149.1 de la Constitución- de disposiciones que adoptan la forma de Real Decreto, siempre que se ajusten a los requisitos que en este caso, precisamente concurren.

7 Vide STS de 6 de julio de 2005 (Ar. 9541), FD PRIMERO: «[...]. Esta Tribunal ignora por qué razón la actora pretende limitar el carácter complementario y de desarrollo normativo del RD 1277/03 a la Ley de 25 de abril de 1986, y en concreto a su artículo 29. La simple lectura del preámbulo del mismo incluso de sus primeros párrafos, ya pone de manifiesto que el reglamento impugnado se propone desarrollar y complementar dos disposiciones con carácter de ley formal: la ya mencionada General de Sanidad y la Ley 16/03, de Cohesión y Calidad del Sistema Nacional de Salud, que precisamente regula con carácter básico las garantías mínimas de seguridad exigibles para la regularización y autorización, por parte de las Comunidades Autónomas, de la apertura y puesta en servicio de centros, servicios y establecimientos sanitarios en su respectiva demarcación territorial. Añadiéndose en el párrafo tercero del mismo preámbulo, que constituye la finalidad del RD 1277/03 la regulación de las bases de autorización de dichos centros, servicios y establecimientos sanitarios de conformidad con lo preceptuado en las Leyes de 25 de abril de 1986 y 28 de mayo de 2003». 
En efecto: refiriéndonos únicamente a la doctrina constitucional que sirve de término de contraste a la demandante, la noción de legislación básica a que se refiere el artículo 149 ha de ser entendida en sentido material, no siendo absolutamente necesario que revista el carácter de ley formal cuando: a) bien careciendo de legislación postconstitucional sobre el tema, el Gobierno regule una materia básica, siempre que de la legislación preconstitucional pueda inferirse claramente cuales sean las bases establecidas sobre la misma; b) bien cuando existiendo normas postconstitucionales que definan lo que resulta básico sobre una materia determinada, la posterior regulación complementaria por vía de reglamento viniese autorizada en virtud de una habilitación legal y esa posterior regulación se refiera a un aspecto de dicha materia cuya naturaleza haga inadecuada e innecesaria su regulación en virtud de Ley formal.

Tanto la Ley General de Sanidad (artículo 29.2) como la de Cohesión y Calidad del Sistema Nacional de Salud (Disposición Final $5^{\text {a)}}$, básicas en la materia, autorizan al Gobierno a dictar las disposiciones complementarias que sean precisas sobre calificación, registro y autorización de centros, servicios y establecimientos sanitarios, tema que constituye el objeto explícito del RD 1277/03, y que desde luego no constituye materia idónea para ser reglada mediante Ley formal».

\section{EL CONGEPTO DE GENTRO, SERVICIO O ESTABLEGI- MIENTO SANITARIO Y SU DEPURACIÓN JURISPRUDEN- GIAL $^{8}$}

Todos los centros y establecimientos sanitarios deberán ser objeto de autorización y registro ${ }^{9}$. Pero ha sido difícil a lo largo del tiempo establecer un concepto y una clasificación omnicomprensiva e intertemporal:

\footnotetext{
${ }^{8}$ Para un estudio más detallado sobre esta materia Vide: Juan Francisco PÉREZ GÁLVEZ, Autorización y registro de centros y establecimientos sanitarios, Bosch, Barcelona, 2003; Juan Francisco PÉREZ GÁLVEZ, Comentarios al Estatuto Marco del Personal Estatutario de los Servicios de Salud, Vol. I, Bosch, Barcelona, 2004; Juan Francisco PÉREZ GÁLVEZ, Incidencia del Estatuto Básico del Empleado Público en el acceso al empleo del personal de los servicios de salud, Instituto Nacional de Administración Pública, Madrid, 2011.

${ }^{9}$ Vide STSJ de Andalucía, Sevilla, de 4 de febrero de 2002 (Ar. 148148).
} 
«En este punto, resulta oportuno hacer unas matizaciones. Tanto los hospitales como las Clínicas son organizaciones sanitarias de alta tecnología médica - es lo que se denomina Asistencia Terciaria-, destinadas a poner todos sus medios, tanto materiales como personales, a disposición de los enfermos, con la finalidad de tratarles y conseguir, en su caso, si ello es posible, su curación.

Pero hay una diferencia entre ambas organizaciones. Generalmente, las Clínicas son de carácter privado, mientras que los Hospitales suelen ser propiedad de instituciones públicas. [...]» ${ }^{10}$.

Lo cierto, es que el concepto y la clasificación de los centros y establecimientos sanitarios pueden responder a diversas motivaciones ${ }^{11}$.

\section{Centro Sanitario.}

El Tribunal Superior de Justicia de Islas Baleares, en sentencia de 26 de marzo de 1999, tiene que enjuiciar una cuestión litigiosa motivada por la incoación de un procedimiento sancionador donde se imputan los siguientes hechos:

$\left.« 1^{\circ}\right)$ que en la fachada del edificio correspondiente al piso del "Instituto de Belleza [...]", existe un rótulo con la siguiente inscripción: "Cirugía y Medicina Estética. Liposucción-Lipoescultura ultrasónica, obesidad, celulitis, arrugas, acné y varices".

$2^{\circ}$ ) la propietaria se niega a dar información, así como a la realización de visita de inspección. Solicitada por la inspección autorización sanitaria y memoria de actividades, éstas no han sido presentadas.

${ }^{10}$ Vide Aurelia María ROMERO COLOMA, La medicina ante los derechos del paciente, Montecorvo, Madrid, 2002, p. 92.

11 Vide STSJ del País Vasco de 7 de septiembre de 2011 (ar. 173438), FJ SEGUNDO: «[...]. a) La empresa discrepa de la Administración, que considera que para que pudiera ser "establecimiento de tejidos", previamente debía ser "centro sanitario", y en concreto "banco de tejidos". La recurrente discrepa y considera que tendría que ser "centro sanitarios", pero no "banco de tejidos"». 
$3^{\circ}$ ) incumplimiento del requerimiento efectuado por la Inspección de Sanidad en acta de 19-5-1995 para que retire en el plazo de una semana el rótulo publicitario que hace referencia a prácticas médicas» $^{12}$.

El Diccionario de uso del español (edición abreviada) María Moliner, Gredos, Madrid, 2008, determina que el significante "centro", tiene, entre otros, los siguientes significados: «6. Establecimiento en que se desarrolla una actividad de enseñanza, sanitaria, comercial, etc. [...]». El mismo diccionario define lo sanitario como: «De [la] sanidad». De la sanidad se dice que es el: «Conjunto de servicios $[. .$.$] que se refieren a la salud pública».$

La unión de los significados descritos nos llevaría a afirmar que un centro sanitario será un lugar donde se desarrolla una actividad consistente en un conjunto de servicios para preservar la salud de los habitantes. Sin embargo, una ambulancia es considerada como un centro sanitario (móvil), y sin embargo no es un lugar, pues se trata de un bien mueble. Su participación en la preservación de la salud también es indirecta, y parece quedar un tanto descolgada del concepto expuesto. Lo mismo puede ocurrir con un barco hospital, o con otros ejemplos en los que puede faltar alguna de estas características. Por todo ello es necesario acuñar un concepto que permita establecer su significación teniendo en cuenta todos los elementos y características que deben confluir para garantizar una adecuada asistencia a los ciudadanos.

Por tanto, será un centro sanitario legalizado aquel en el que concurran unos elementos objetivos, subjetivos, conectivos, con una determinada finalidad y que así resulte autorizado por la Administración sanitaria en virtud de una previa habilitación legal o reglamentaria. Es decir, «todo aquel bien mueble o inmueble en el que tras una correcta identificación, se aúnen los espacios fisicos necesarios

12 Vide STSJ de las Islas Baleares, de 26 de marzo de 1999, FD PRIMERO, donde frente a lo expuesto se argumenta:

$\left.« 1^{\circ}\right)$ que no se niega la existencia del rótulo si bien se discrepa en la valoración del hecho ya que, en realidad, el Centro de Belleza gestiona dichas intervenciones médicas que se realizan en los centros sanitarios correspondientes.

$\left.2^{\circ}\right)$ que la autorización exigida en el Decreto [...] lo es para "centros sanitarios" y el instituto de belleza regentado por la demandante no lo es ya que no hay instalaciones sanitarias y toda conexión con la actividad médica es el hecho de que la doctora [...], en determinados días, pasa consulta y asesora.

$\left.3^{\circ}\right)$ no se produjo obstrucción alguna a la actividad instructora sino que simplemente se manifestó el deseo de que se le informase de sus derechos y obligaciones al respecto. Por otra parte no consta que en el acta se reflejase el apercibimiento oportuno de las consecuencias derivadas de la negativa la inspección que se pretendía realizar en el mismo momento». 
(área de recepción, sala de espera, área clínica, etc, uno o varios), el equipamiento y dotación de material y personal sanitario titulado, donde las técnicas o medios de carácter sanitario que utilizan tienen como finalidad principal o accesoria, ya sea preventiva, diagnóstica, terapéutica, rehabilitadora o didáctica, la curación o mejora de la salud del ciudadano y que previamente ha sido autorizado por la Administración sanitaria conforme a las disposiciones legales o reglamentarias vigentes, para este fin» ${ }^{13}$.

El Real Decreto 1277/2003, de 10 de octubre, art. 2.1.a), define como centro sanitario «el conjunto organizado de medios técnicos e instalaciones en el que profesionales capacitados, por su titulación oficial o habilitación profesional, realizan básicamente actividades sanitarias con el fin de mejorar la salud de las personas. Los centros sanitarios pueden estar integrados por uno o varios servicios sanitarios, que constituyen su oferta asistencial». Sólo tendrán esta consideración los que se recogen en esta disposición.

A la vista de estas referencias legales hoy no sería posible llegar a un pronunciamiento como el que establece la STSJ de las Islas Baleares de 26 de marzo de 1999 (Ar. 573):

«Pues bien, desde el momento en que la propia Administración demandada reconoce (apartado II de su escrito de contestación, párrafo $\left.6^{\circ}\right)$ que «ha quedado demostrado que los actos médicos de "ci-

13 Vide Ley 37/62, de 21 de julio, de Hospitales, BOE de 23 de julio, núm. 175: «A tales principios y premisas responde que se consideren los Hospitales como centros de asistencia, con el más amplio sentido de las distintas fases o clases de medicina, inclusive la formación del personal o la investigación científica, y desde luego abiertos para toda la población, sin perjuicio de limitaciones derivadas de prioridades determinadas por su destino o de su ámbito y especialidad». Vide LGS, art. 65.2: «El hospital es el establecimiento encargado, tanto del internamiento clínico, como de la asistencia especializada y complementaria que requiera su zona de influencia». Vide José ORTIZ DÍAZ, "Hacia una reordenación de la sanidad pública española: el problema hospitalario”, RAP, 51, (1966), p. 164: «El hospital, a más de potenciar la función asistencial de medicina curativa, deberá realizar medicina preventiva y de rehabilitación y recuperación del enfermo. En suma, proporcionar una "asistencia integrativa"». En la p. 168, nota 30 establece: «El hospital de nuestros días - se dice- es un centro de irradiación de conocimientos y actividades técnicas, encargadas de velar por la salud de la población. Tiene que disponer de los medios necesarios para formular un diagnóstico inmediato, para prescribir el tratamiento adecuado y para aplicar, cuando así proceda, medidas de readaptación sin pérdida de tiempo». Por ello en esta misma página incluye la definición de hospital que da la O.M.S. en 1957: «El hospital es parte integrante de una organización médica y social, cuya misión consiste en proporcionar a la población una asistencia médico-sanitaria completa, tanto curativa como preventiva y cuyos servicios llegan hasta el ámbito familiar; el hospital es también un centro de formación de personal sanitario y de investigación». Vide Ley 41/2002, de 14 de noviembre, básica reguladora de la autonomía del paciente y de derechos y obligaciones en materia de información y documentación clínica, art. 3. Las definiciones legales: «Centro sanitario: el conjunto organizado de profesionales, instalaciones y medios técnicos que realiza actividades y presta servicios para cuidar la salud de los pacientes y usuarios».

Revista Andaluza de Administración Pública

ISSN: 0034-7639, núm. 84, Sevilla, septiembre-diciembre (2012), págs. 41-88 
rugía, liposucción, lipoescultura ultrasónica” y, en general, aquellos que precisen intervenciones quirúrgicas, no se realizaban en el centro, ni por cuenta de éste» y que «se acepta, como hecho probado, que el centro carece de instalaciones al efecto, y por todo ello se considera innecesaria una nueva inspección [...]»; debe entenderse que el Centro de Belleza que nos ocupa no puede ser calificado como «centro, servicio o establecimiento sanitarios» ya que no se prestan los servicios sanitarios descritos en el precepto arriba mencionado».

\section{Delimitación respecto a figuras afines.}

2.1. El "servicio sanitario" o "unidad asistencial" como objeto de controversia jurídica.

La oferta asistencial de los centros sanitarios podrá estar integrada por uno o varios servicios o unidades asistenciales. Además, también han sido catalogados los servicios sanitarios integrados en una organización no sanitaria. Son servicios que realizan actividades sanitarias pero que están integrados en organizaciones cuya principal actividad no es sanitaria (prisión, empresa, balneario, residencia de tercera edad, etc).

El Diccionario de uso del español (edición abreviada) María Moliner, Gredos, Madrid, 2008, define el "servicio" como: «1. Acción de servir. 2. Actividad que consiste en servir. 4. Actividad económica destinada a satisfacer determinadas demandas de los ciudadanos, sin crear bienes materiales. 6. Organización oficial o privada destinada a prestar cierto servicio. Sección de una empresa, organismo, etc., que presta determinado servicio».

El Diccionario de la Lengua Española, publicado por la Real Academia en su vigésimo primera edición, 1992, definía el "servicio" como: «18. Organización y personal destinados a cuidar intereses o satisfacer necesidades del público o de alguna entidad oficial o privada. 22. Prestación humana que satisface alguna necesidad del hombre que no consiste en la producción de bienes materiales. El que una empresa autorizada para prestar un determinado servicio público, realiza en función de sus propios intereses y de los de los usuarios. Organización municipal, provincial, nacional, etc, destinada a vigilar y proteger la salud pública».

Por tanto un servicio sanitario es una organización pública o privada, dotada de personal, destinada a satisfacer una o varias necesidades sanitarias. 
Vuelven a confluir elementos subjetivos, objetivos y conectivos. Sin embargo es necesario destacar que una organización significa también: «Acción y efecto de organizar y organizarse. Conjunto de personas con los medios adecuados que funcionan para alcanzar un fin determinado. Disposición, arreglo, orden». Dicho de otro modo, un centro o establecimiento sanitario puede organizarse internamente, de forma que las personas (profesionales) y los medios funcionen dispuestos en virtud del fin que pretenden atender.

Es de sobra conocido que los hospitales se organizan en virtud de las especialidades que prestan a los ciudadanos ${ }^{14}$, y estas especialidades se organizan en torno a un jefe de servicio y al resto de personal y medios materiales que forman parte del mismo. Por tanto se puede diferenciar un servicio de ginecología, cirugía, medicina interna, traumatología, cuidados intensivos, etc. Nadie dice "trabajo en la especialidad de medicina interna", sino "trabajo en el servicio de medicina interna", y sin embargo si se afirma "mi especialidad es la de medicina interna". El carácter de organización, disposición, orden dentro del centro sanitario, es el dato que nos muestra como "el todo es más que la suma de las partes o servicios".

Esta es la clave para comprender el concepto: "Un servicio sanitario es la acción y efecto de organizar y organizarse (profesionales y medios) en torno a una especialidad científica sanitaria para conseguir un fin dentro de un centro o establecimiento sanitario" ${ }^{\prime 5}$. En este sentido resulta fundamental su responsable ${ }^{16,17}$, es decir, el je-

14 Vide LGS, art. 15: «1. Una vez superadas las posibilidades de diagnóstico y tratamiento de la atención primaria, los usuarios del Sistema Nacional de Salud tienen derecho, en el marco de su Área de Salud, a ser atendidos en los servicios especializados hospitalarios.

2. El Ministerio de Sanidad y Consumo acreditará servicios de referencia, a los que podrán acceder todos los usuarios del Sistema Nacional de Salud una vez superadas las posibilidades de diagnóstico y tratamiento de los servicios especializados de la Comunidad Autónoma donde residan».

15 Vide Ley 41/2002, de 14 de noviembre, básica reguladora de la autonomía del paciente y de derechos y obligaciones en materia de información y documentación clínica, art. 3. Las definiciones legales: «Servicio sanitario: la unidad asistencial con organización propia, dotada de los recursos técnicos y del personal cualificado para llevar a cabo actividades sanitarias». Vide: STS de 12 de julio de 1999 (Ar. 6756), donde se determina que no se puede hacer desaparecer la sección de urgencias de un hospital mediante una modificación del Reglamento de Régimen Interior; STS de 22 de mayo de 2000 (Ar. 4537), donde se impugna el procedimiento seguido para la creación de un servicio hospitalario.

${ }^{16}$ Vide José Manuel MARTÍN BERNAL, Responsabilidad médica y derecho de los pacientes, La Ley, Madrid, 1998, p. 296: «Los elementos estructurales que caracterizan esta modalidad vertical de la división del trabajo médico, de acuerdo con Wilheim, son los siguientes: 1) el orden jerárquico de distribución de deberes como los de instrucción, control y vigilancia del superior, y la obligación de los subordinados de cumplir las órdenes de sus superiores jerárquicos; 2) la relación de dependencia de los subordinados en el contexto de la supra-subordinación; y 3) la delegación que afecta no sólo a la actividad del colaborador su- 


\section{fe de servicio, como elemento de interconexión con los demás y la dirección del centro ${ }^{18}$.}

El Real Decreto 1277/2003, de 10 de octubre, en su art. 2.1.b) determina la definición de servicio sanitario en los siguientes términos: «unidad asistencial, con organización diferenciada, dotada de los recursos técnicos y de los profesionales capacitados, por su titulación oficial o habilitación profesional, para realizar actividades sanitarias específicas. Puede estar integrado en una organización cuya actividad principal puede no ser sanitaria».

bordinado sino también a lo que puede suponer de desplazamiento de competencias y responsabilidad como propias de funciones ajenas».

17 Vide: STS de 10 de noviembre de 1999 (Ar. 2658); STS de 2 de octubre de 2001 (Ar. 9031).

18 Vide Sentencia del Tribunal Superior de Justicia de Baleares, Sala de lo Social, de 7 de febrero de 1992 (Ar. 521), F.D. Primero: «[...]. En ejecución de tal resolución judicial el Director-Gerente del Hospital Can Misses remitió el 7-12-1990 un escrito al señor T., cuyo último párrafo presenta la siguiente literal redacción: "debo también comunicarle que por corresponder legalmente a la Dirección Médica la supervisión y coordinación de los servicios médicos, se abstenga a (sic) tomar ninguna iniciativa como Jefe de Servicio que no haya sido formulada por escrito y aceptada por la mencionada Dirección"» y F.D. Tercero: «El vigente Reglamento sobre estructura, organización y funcionamiento de los hospitales gestionados por el Instituto Nacional de la Salud no detalla el contenido de las funciones que compete desempeñar al titular de una Jefatura de servicios médicos, limitándose a decir en su art. 26 que "serán responsables del correcto funcionamiento de las mismas y de la actividad del personal a ellos adscrito, así como la custodia y utilización adecuada de los recursos materiales que tengan asignados". No deben existir inconvenientes por tanto, que esa indefensión se supla con la relación de funciones que enumera el art. 71 de la O.M. 7-7-1972, entendiendo subsistentes, cuando menos, todas aquellas que no aparecen claramente dejadas sin efecto por la normativa posterior, pues no es dudoso que en la actualidad, sigue correspondiendo al Jefe de Servicio ejercer la función rectora del Servicio coordinando la actividad profesional de las Secciones y Unidades Clínicas que lo integren, así como la utilización de los medios materiales, y también asistir responsablemente a los enfermos, lo mismo en cuanto a su atención directa, como la correcta utilización de los medios diagnósticos y terapéuticos que se les apliquen, aspectos ambos que parecen consustanciales a un puesto de tales características. Es cierto que la actuación profesional de los Jefes de Servicio se desenvuelve bajo la dependencia inmediata del Director Médico. Así lo indica de manera expresa el art. 25.2 del Reglamento y lo reitera el art. 10.2 cuando en su apartado a) determina que corresponde al Director Médico la dirección, supervisión, coordinación y evaluación del funcionamiento de los servicios médicos. Sin embargo, esta relación de subordinación en que se encuentra el Jefe de Servicio respecto del Director Médico no autoriza a desnaturalizar el cargo del primero, despojando de todo contenido práctico a las potestades de organización y dirección del servicio que lleva aparejado situación que se produce al instaurarse un sistema de control preventivo, absoluto y global, como el que establece la controvertida comunicación de 7-12-1990, ya que abarca la totalidad de las funciones que incumbe desarrollar al titular de la jefatura sin discordancia ni tan siquiera facetas organizativas y de pura asistencia médica, de modo que, aplicado dicho sistema hasta sus últimas consecuencias, conduce al absurdo de que el Jefe de Servicio se vea obligado a consultar con su superior - y con carácter vinculante- hasta las decisiones concernientes al tratamiento clínico y curativo de sus enfermos por insignificantes que sean, como subraya acertadamente la resolución recurrida. No hay responsabilidad sin margen reconocido y efectivo de libertad, como también recuerda el Juez "a quo". En definitiva, el Director Médico puede lícitamente en 
Con estas referencias legales no tienen cabida consideraciones como las que se enumeran en la STS de 6 de julio de 2005 (Ar. 9541), FD PRIMERO, donde se alega que el RD 1277/2003 excede de la habilitación legal concedida por la Ley General de Sanidad, pues «el artículo 29 de la Ley precitada únicamente se refiere a los "centros y establecimientos sanitarios", de suerte que el concepto de "servicios" cuya definición - artículo $2^{\circ}$ - los configura como unidad asistencial con organización diferenciada y dotada de los recursos técnicos y profesionales capacitados, es extraño a la habilitación otorgada por la Ley de 25 de abril de 1986».

En otros casos, lo que se reprocha es el propio concepto de unidad asistencial tal y como se encuentra definida en el RD 1277/2003, pues se entiende que incide o coarta las expectativas profesionales de aquellos que formulan el recurso ${ }^{19}$.

Aunque no se encuentra recogido en el Real Decreto 1277/2003, de 10 de octubre, va tomando consistencia un nuevo tipo de criterio de ordenación del personal, que viene a ser un sustitutivo del "servicio sanitario", y que se caracteriza esencialmente por la asignación del tratamiento de determinados procesos asistenciales, y por tanto, configurados con profesionales de diversas especialidades sanitarias.

La unidad de gestión clínica es la estructura organizativa en la que se materializa esta formulación instrumental en los centros sanitarios. Está integrada por personas de ámbito multiprofesional pertenecientes a distintos estamentos, disciplinas y categorías, de uno o varios distritos hospitalarios o áreas de gestión sanitaria, que prestan una atención integral, en el ámbito de su competencia, a la población asignada para lo que se otorgan unos recursos planificados. Se vertebra en torno a la afinidad de las áreas de referencia del conocimiento en salud de sus profesionales y a las necesidades sanitarias y de protección de la salud de los ciudadanos, a los que específicamente atienden.

el recto cumplimiento de los deberes de su cargo impartir instrucciones más o menos específicas a los Jefes de Servicio que de él dependan; puede, inclusive, exigir que se recabe por anticipado su autorización en cuanto a la adopción de medidas relacionadas con los aspectos más importantes y trascendentes para el buen funcionamiento del servicio; puede, desde luego, revocar las órdenes que considere son incorrectas, desacertadas o que no se acomoden a sus directrices y criterios. Pero, reconocida normativamente la sustantividad del puesto dentro del organigrama del Hospital, lo que tiene vedado es suplantar "de facto" al Jefe de Servicio en el desempeño de su cometido específico».

${ }^{19}$ Vide: STS de 6 de julio de 2005 (Ar. 9541), FD TERCERO Y CUARTO; STS de 7 de marzo de 2006 (Ar. 1761). 
Evidentemente, las áreas de referencia del conocimiento en salud a las que me he referido, se corresponden con la definición de profesiones sanitarias tituladas y reguladas en los grupos de nivel licenciado y diplomado y los títulos oficiales de especialistas en ciencias de la salud respectivos, previstos en el artículo segundo de la Ley 44/2003, de 21 de noviembre, de ordenación de las profesiones sanitarias, con las adaptaciones que procedan respecto a los nuevos títulos universitarios de grado y posgrado.

Dependen orgánica y funcionalmente de la dirección gerencia de los centros sanitarios a los que se encuentran adscritas, sin perjuicio de la dependencia funcional que les corresponda para el cumplimiento de sus fines y objeti$\operatorname{vos}^{20}$. Un buen ejemplo, lo constituye la Ley 9/2010, de 23 de diciembre, de personal estatutario de Instituciones Sanitarias de Cantabria, art. 13:

«Criterios de ordenación del personal.

1. Las personas responsables de los servicios y unidades, siguiendo los criterios establecidos por la dirección del centro o institución, ejercerán la dirección funcional del personal que tenga asignado.

2. Las unidades orgánicas podrán constituirse en Unidades de Gestión Clínica, carentes de personalidad jurídica, que desarrollarán sistemas de gestión autónomos, de acuerdo con los criterios, límites y autorización de la Consejería competente en materia de sanidad.

3. Asimismo podrán constituirse Áreas de Gestión Clínica, carentes de personalidad jurídica, que serán el conjunto integrado de unidades orgánicas de carácter multidisciplinar que desarrollan sistemas de gestión autónomos en relación con los procesos asistenciales que se determinen, de acuerdo con los criterios, límites y autorización de la Consejería competente en materia de sanidad.

4. Tanto las Unidades de Gestión Clínica como las Áreas de Gestión Clínica constarán en la correspondiente plantilla orgánica. Si de la organización resultante se derivaran modificaciones de las condiciones de trabajo, éstas deberán ser negociadas con carácter previo en la correspondiente mesa de negociación».

${ }^{20}$ Vide Borrador del Proyecto de Decreto de Ordenación y Regulación de la Gestión Clínica en el Servicio Andaluz de Salud, versión final junio 2011, art. 3. 
En el supuesto reproducido, llama poderosamente la atención la asignación del término unidad orgánica, a lo que normalmente se ha venido denominando "servicio", y la reiteración en el dato de "carencia de personalidad jurídica".

Para justificar esta opción se hace referencia a la Ley 44/2003, de 21 de noviembre, de Ordenación de las Profesiones Sanitarias, al disponer que los profesionales sanitarios desarrollan, entre otras, funciones en los ámbitos asistencial, investigador, docente, de gestión clínica, de prevención y de información y educación sanitarias (art. 4), y establece que la atención sanitaria integral supone la cooperación multidisciplinar, la integración de los procesos y la continuidad asistencial. Define además, el equipo de profesionales, como la unidad básica en la que se estructuran, de forma multiprofesional e interdisciplinar, los propios profesionales y el resto del personal que apoya el desarrollo de las actuaciones asistenciales. También dispone que los equipos profesionales, una vez constituidos y aprobados en el seno de las organizaciones o instituciones sanitarias, serán reconocidos y apoyados y sus actuaciones facilitadas por los órganos directivos y gestores de las mismas (art. 9). Establece que las administraciones sanitarias, los servicios de salud o los órganos de gobierno de los centros y establecimientos sanitarios, según corresponda, establecerán los medios y sistemas de acceso a las funciones de Gestión Clínica, a través de procedimientos en los que habrán de tener participación los propios profesionales y que el ejercicio de estas funciones estará sometido a la evaluación del desempeño y de los resultados (art. 10).

Sin duda, la aparición de nuevas necesidades y demandas en una sociedad en continuo crecimiento y expansión como la española, titular real de un sistema sanitario público y en donde las nuevas tecnologías y el conocimiento ocupan un lugar privilegiado, hace necesario establecer un marco general organizativo renovado. Para garantizar la sostenibilidad del sistema, se incorpora una cultura de corresponsabilidad de los profesionales en el control del gasto sanitario, al tiempo que es imprescindible adelgazar las estructuras administrativas simplificando las mismas y descentralizando la gestión al objeto de reducir sus costes y lograr la mayor eficacia. Por ello, se posibilita una nueva regulación del marco funcional en el que históricamente han desempeñado sus actuaciones los profesionales sanitarios del sistema sanitario público y hacerlo desde la eficiencia, desde los nuevos roles profesionales sanitarios y desde la orientación hacia los resultados en salud. Para intensificar el desarrollo de la gestión clínica:

«Procede, en consecuencia, de acuerdo con el marco legal vigente, a continuar introduciendo y concretando cambios en la organiza- 
ción de los servicios sanitarios con arreglo a los criterios que configuran la gestión clínica y en orden a conseguir un triple objetivo:

Fomentar el incremento de la capacidad auto-organizativa de los profesionales para desarrollar niveles crecientes de autogestión de sus actividades clínicas y de salud pública, así como optimizar el uso de los recursos que utilizan, incorporando su corresponsabilidad a la gestión de los servicios sanitarios.

Impulsar la agrupación funcional y eficiente de los profesionales - en tanto en cuanto generan conocimiento específico basado en evidencias sobre el coste-efectividad de las técnicas y los procedimientos clínicos- en nuevos modelos organizativos coherentes con niveles acreditados de calidad objetivamente medidos y reconocidos. Se persigue con ello orientar la atención sanitaria, de acuerdo con los procesos asistenciales y de protección en el marco de los planes y estrategias transversales de salud, para favorecer la reducción de la variabilidad en la práctica clínica y en las intervenciones en salud pública.

Conformar un marco óptimo para el máximo desarrollo y aplicación efectiva del conjunto de herramientas operativas y funcionales de carácter estratégico que el Sistema sanitario Público de Andalucía ha venido incorporando desde hace más de una década, especialmente en los que se refiere a la gestión por competencias, los procesos asistenciales integrados y la acreditación de la calidad, adaptándolas a la composición específica de cada unidad y a las particulares circunstancias de cada momento» ${ }^{21}$.

${ }^{21}$ Ibídem, pp. 4.5. En el art. 1 de este controvertido texto, se determina su objeto y ámbito de aplicación, en los siguientes términos:

«1. Este Decreto tiene por objeto establecer y definir la estructura organizativa renovada del Servicio Andaluz de Salud que implica un desarrollo efectivo de la Gestión Clínica. Ello supone la reducción de estructuras directivas, la simplificación del modelo organizativo y la regulación de aspectos esenciales tales como la autorización, estructura y funcionamiento de las Unidades de Gestión Clínica y de sus órganos de dirección y participación.

2. El ámbito de aplicación es la totalidad de actuaciones de atención sanitaria, incluyendo las de protección, promoción y prevención de la Salud Pública, que se desarrollan en todos los ámbitos de competencia del Servicio Andaluz de Salud.

3. Se consideran centros sanitarios a los efectos de pertenencia, adscripción y dependencia jerárquica y funcional de las Unidades de Gestión Clínica los Hospitales con sus Áreas hospitalarias, los Distritos de Atención Primaria y las Áreas de Gestión Sanitaria cuya denominación queda modificada por la disposición adicional tercera del presente Decreto pasando a ser denominadas Áreas integrales de Salud del sistema sanitario público de Andalucía». 
El fundamento de esta nueva modalidad de configuración de la gestión clínica es una organización funcional de la atención sanitaria basada en una red distribuida de espacios organizativos de ámbito multiprofesional.

El objetivo fundamental se centra en prestar una atención sanitaria integral y de alta calidad en nuevos espacios compartidos que cuentan con la participación efectiva de los ciudadanos y en los que los profesionales sanitarios se integran en equipos configurados con criterios de agrupación eficiente en base a la afinidad de sus ámbitos de conocimiento específico, en el seno de uno o varios centros asistenciales, enlazando las necesidades de salud de los ciudadanos y las expectativas legítimas de los profesionales.

En el seno de la gestión clínica se materializa la gestión por valores, modelo descentralizado y participativo de dirección estratégica que se basa en la formulación de la visión del sistema sanitario público a partir de la identificación del conjunto de sus valores esenciales, la armonización de los diferentes aspectos de los mismos y su asunción explícita por cada una de las unidades organizativas y sus responsables, como elemento de legitimación social y soporte estratégico para la toma de decisiones en la planificación de la actividad de los equipos asistenciales, así como para su aplicación práctica a la provisión de servicios de salud en el nuevo escenario compartido entre los ciudadanos, los profesionales que les prestan servicios de salud y los administradores sanitarios, que supone la gestión clínica. Por todo ello, se fundamenta también en la gestión eficiente por parte de los profesionales de las partidas presupuestarias de gasto y consumos más representativos y con impacto real en la actividad asistencial o de salud pública que éstos desarrollan.

Como equivalencia a la jefatura de servicio, se crea el puesto de director de unidad de gestión clínica que tendrá categoría profesional de cargo homologable en términos retributivos con el rango de jefe de servicio para los profesionales del grupo Al y con el rango de supervisor general, jefe de bloque o similar, para los profesionales del grupo A2.

\subsection{Establecimiento sanitario.}

La clasificación del Real Decreto 1277/2003, de 10 de octubre, por el que se establecen las bases generales sobre autorización de centros, establecimientos y servicios sanitarios, determina los establecimientos sanitarios que pueden operar en nuestro país, a saber: 
- E.1 Oficinas de farmacia: establecimientos sanitarios privados de interés público, sujetos a la planificación sanitaria que establezcan las Comunidades Autónomas, en las que el farmacéutico titular-propietario de aquéllas, asistido, en su caso, de ayudantes o auxiliares, debe prestar a la población los servicios básicos recogidos en el artículo 1 de la Ley 16/1997, de 25 de abril, de Regulación de los Servicios de las Oficinas de Farmacia.

- E.2 Botiquines: establecimientos sanitarios autorizados para la tenencia, conservación y dispensación de medicamentos y productos sanitarios, por la existencia de dificultades especiales de accesibilidad a una oficina de farmacia.

- E.3 Ópticas: establecimientos sanitarios donde, bajo la dirección técnica de un diplomado en Óptica y Optometría, se realizan actividades de evaluación de las capacidades visuales mediante técnicas optométricas; tallado, montaje, adaptación, suministro, venta, verificación y control de los medios adecuados para la prevención, detección, protección, mejora de la agudeza visual; ayudas en baja visión y adaptación de prótesis oculares externas.

- E.4 Ortopedias: establecimientos sanitarios donde, bajo la dirección técnica de personal con la titulación oficial, cualificación profesional, o experiencia requeridas conforme a la legislación vigente, se lleva a cabo la dispensación, con adaptación individualizada al paciente, de productos sanitarios de ortopedia considerados como prótesis u ortesis, así como ayudas técnicas destinadas a paliar la pérdida de autonomía o funcionalidad o capacidad física de los usuarios.

- E.5 Establecimientos de audioprótesis: establecimientos sanitarios donde, bajo la dirección técnica de personal con la titulación oficial, cualificación profesional o experiencia requeridas conforme a la legislación vigente, se lleva a cabo la dispensación, con adaptación individualizada al paciente, de productos sanitarios dirigidos a la corrección de deficiencias auditivas.

El lugar donde habitualmente se ejerce una industria o profesión se define como establecimiento. En este caso se trataría de una industria o profesión sanitaria. Sin embargo, esta definición no aclara si su significado es idéntico al de centro sanitario. ¿Porqué? Esto es así, porque centros sanitarios lo son todos ${ }^{22}$.

22 Vide Adolfo SERIGO SEGARRA y Pedro PORRAS ORÚE, La planificación de la asistencia hospitalaria en España, Patronato Nacional de Asistencia Psiquiátrica, Madrid, 1966, pp. 94 y 95: «Pero, aunque el concepto de la Ley es claro, corresponde a las normas reglamentarias perfilarlo y desarrollarlo hasta su detalle más pequeño. De ahí que un concepto reglamentario de hospital haya de destacar los requisitos necesarios y, además, suficientes par que a un determinado establecimiento se le pueda atribuir el carácter le- 
Guando continuamos precisando el perfil jurídico de cada uno de ellos, aparece una categoría especial que son los establecimientos sanitarios (es lo que sucede cuando hablamos del todo y la parte, o del género y la especie). Es decir, son los centros, en los que concurren las características señaladas.

Así lo entiende la STSJ de Madrid, de 27 de mayo de 2010 (Ar. 298230), donde resuelve la controversia suscitada por la desestimación del recurso de alzada interpuesta contra la desestimación presunta de la autorización para la instalación de una consulta/gabinete de podología en la planta quinta del centro comercial "El Corte Inglés", sito en la C/ Goya n 76 de Madrid:

«La recurrente afirma que la actividad desarrollada por [...] es claramente un servicio sanitario o unidad asistencial y no la propia de un establecimiento sanitario como indica la resolución administrativa. [...]. Expresa que la definición de establecimiento sanitario que le atribuye la Administración no se ajusta a la actividad que desarrolla [...]. Sin embargo, la definición de servicio sanitario o unidad asistencial si se ajusta a su actividad. [...].

En contra de lo manifestado por la Comunidad de Madrid, esta Sala no admite que la actividad que desarrolla la actora sea la propia de un centro de ortopedia que efectivamente tiene la consideración de establecimiento sanitario -Anexo I Real Decreto 1277/2003- sino que es una consulta de podología regulada en el Anexo II del Real Decreto 1277/2003, como unidad asistencial».

Por eso la legislación estatal y autonómica los clasifica como centros, servicios o establecimientos sanitarios, intentando delimitar de alguna forma con mayor precisión el objeto de su regulación, aunque sin determinar su contenido. Una buena prueba de esta afirmación y de la dificultad que presenta esta categoría jurídica es la definición de establecimiento que se encuentra en el Real Decreto 1277/2003, de 10 de octubre, art. 2.1.c): «conjunto organizado de medios técnicos e instalaciones en el que profesionales capacitados por su titulación oficial o habilitación profesional, realizan básicamente actividades sanitarias de dispensación de medicamentos o de adaptación individual de productos sanitarios». Concepto o definición casi

gal de hospital. En concordancia con lo prevenido en la ley, son tres los requisitos que han de tener los establecimientos para poderse titular hospitales: Primero: Tener como finalidad primordial la prestación de asistencia médica, quirúrgica o médico-quirúrgica. [...]. Segundo: Poseer una capacidad de internamiento. [...]. Tercero: El tercer requisito es una condición formal impuesta por la Ley y que debe precisarse en el reglamento. $[\ldots]$ ». 
idéntico al de centro sanitario contemplado por esta disposición. Y además, tal como se recoge en el concepto de centro sanitario, los profesionales que están al frente de un establecimiento sanitario, también buscan el "fin de mejorar la salud de las personas", que sería la expresión que haría esta definición idéntica a la de centro sanitario. Estas apreciaciones dan idea de lo poco acertada que resulta la definición de establecimiento sanitario que incorpora el Real Decreto estatal.

Por eso, en ocasiones, nos encontramos con supuestos como el contemplado en la STSJ de la Rioja, de 9 de noviembre de 2010 (ar. 58), FD TERCE$\mathrm{RO}$, donde la exigencia de un equipo de reanimación cardiopulmonar a un establecimiento de óptica, vulnera la normativa básica, y por tanto, procede a declararlo nulo de pleno derecho.

\subsection{Actividad sanitaria.}

Por último sería necesario definir que es una actividad sanitaria. El concepto de actividad es en sí un concepto vago. Sirvan las siguientes palabras para intentar precisar algo más su contenido ${ }^{23}$ :

«La acepción más amplia de cuantas se refieren al obrar humano es la de comportamiento, comprensiva, $[\ldots]$, tanto del hacer como del soportar, según las circunstancias.

La actividad que asumiría el segundo escalón en sentido descendente, queda, en nuestro entender, limitada al hacer, y no comprende, por tanto, el soportar; supone ya algo efectivo frente a lo meramente potencial: traducir en movimiento facultades preexistentes.

Jurídicamente, tal actividad se sustancia en la consideración de un conjunto de actos y operaciones, unificados en el plano funcional por la unicidad del fin perseguido.

23 Vide Manuel MARTÍN GONZÁLEZ, Sanidad pública: concepto y encuadramiento, Vol. III, Madrid, 1970, pp. 816-820. En las pp. 828 y 829, precisa: «A veces esa proyección de las actuaciones de la Administración hacia sus propios fines [...] se ha calificado - acaso con mayor rigor- con el nombre de acción, con el que resultaría ese "entender de la Administración hacia fines concretos".

Por nuestra parte, no creemos que exista inconveniente en usar indistintamente ambos términos como se hace en este trabajo, pese a que un acreditado sector doctrinal considera la acción, en una significación más estricta, como una de las fases de actuación del acto». 
La caracterización de tales "operaciones" o "actuaciones" no es, sin embargo, uniforme. Prescindiendo de la discutida adscripción a la categoría de los hechos jurídicos o de los actos por tales operaciones, cuyo concepto ha sido elaborado por la Teoría general del Derecho, se pueden entender, según los autores, cosas diversas. O bien simples modificaciones de la realidad, o bien tanto "materializaciones de la voluntad directamente modificativas de la realidad" como "pronunciamientos (resoluciones) precedidos por otros actos relevantes", o bien un conjunto de actos conectados entre sí, "con el fin de servir cada uno como presupuesto del siguiente para un mismo resultado práctico, pero sin constituir el conjunto ejercicio de una función".

Obviamente, el acto puede distinguirse de la actividad, en cuanto "lo hecho" se distingue "del hacer"; la "obra", "del trabajo". Pero no se puede olvidar que el acto - desde el que se viene estudiando tradicionalmente la actividad- "está constituido por una infinidad de momentos parciales que, en la realidad, sólo se destacan un poco menos claramente que el acto mismo" [...]; la actividad se refiere tanto a la obra como al trabajo, tanto al acto como al conjunto de operaciones o actuaciones que lo han hecho posible.

En cualquier caso, dichas operaciones concurren a determinar el concepto de actividad, en cuanto constituyen - al igual que las declaraciones- ${ }^{-}$el momento de actuación del acto [...].

Consistiendo la actividad en actos y operaciones, y dada la predicada instrumentalidad de éstas respecto a aquéllos, se hace preciso señalar las condiciones que deben concurrir para que el conjunto de una serie de actos y operaciones se considere por el ordenamiento como tipo de actividad autónoma e independiente. [...].

Es pues, esta valoración funcional, y en cuanto tal teleológica, y no la subjetiva u orgánica, la que unifica aquellos y éstas, individualizando la actividad por esa proyección de todos ellos al mismo y único resultado y proporcionado a la vez el criterio que permite en cada caso reconducir a la normativa de la actividad cada uno de los actos».

Por tanto la actividad sanitaria consiste en un "hacer", es decir, traducir en movimiento facultades preexistentes (otorgadas de modo expreso mediante una autorización a la(s) persona(s) física(s) o jurídica(s) que es/son titular(es) o ejerce(n) en el centro, servicio o establecimiento) y por tanto ejecuta actos y 
operaciones que forman parte de las prestaciones asistenciales de carácter sanitario declaradas en la memoria descriptiva, para conseguir el fin para el que fue autorizado.

El Real Decreto 1277/2003, de 10 de octubre, por el que se establecen las bases generales sobre autorización de centros, servicios y establecimientos sanitarios, en su art. 2.1.d) define la actividad sanitaria como: «conjunto de acciones de promoción, prevención, diagnóstico, tratamiento o rehabilitación, dirigidas a fomentar, restaurar o mejorar la salud de las personas realizadas por profesionales sanitarios».

\section{LAS GLASES DE GENTROS, SERVICIOS O ESTABLEGI- MIENTOS SANITARIOS Y SU RELAGIÓN CON LA GA- RANTÍA CONSTITUCIONAL DEL EJERGICIO DE LAS PROFESIONES SANITARIAS TITULADAS}

Según el diccionario de la Real Academia de la Lengua, profesión es el "empleo, facultad u oficio que cada uno tiene y ejerce públicamente”. La Ley de Ordenación de las Profesiones Sanitarias determina en el preámbulo: «El concepto de profesión es un concepto elusivo que ha sido desarrollado desde la sociología en función de una serie de atributos como formación superior, autonomía y capacidad auto-organizativa, código deontológico y espíritu de servicio, que se dan en mayor o menor medida en los diferentes grupos ocupacionales que se reconocen como profesiones. A pesar de dichas ambigüedades y considerando que nuestra organización política sólo se reconoce como profesión existente aquélla que está normada desde el Estado, los criterios a utilizar para determinar cuales son las profesiones sanitarias, se deben basar en la normativa preexistente. Esta normativa corresponde a dos ámbitos: el educativo y el que regula las corporaciones colegiales. Por ello en esta Ley se reconocen como profesiones sanitarias aquellas que la normativa universitaria reconoce como titulaciones del ámbito de la salud, y que en la actualidad gozan de una organización colegial reconocida por los poderes públicos. Por otra parte, existe la necesidad de resolver, con pactos interprofesionales previos a cualquier normativa reguladora, la cuestión de los ámbitos competenciales de las profesiones sanitarias manteniendo la voluntad de reconocer simultáneamente los crecientes espacios competenciales compartidos interprofesionalmente y los muy relevantes espacios específicos de cada profesión. Por ello en esta Ley no se ha pretendido determinar las competencias de unas y otras profesiones de una forma cerrada y concreta sino que establece las bases para que se produzcan estos pactos entre profesiones, y que las praxis cotidianas de los profesionales en organizaciones crecientemente multidisciplinares evolucionen de forma no conflictiva, sino cooperativa y transparente». 
En consecuencia el número de profesiones susceptibles de ser ejercidas es, en principio muy amplio, y a ello se refiere el derecho a la libre elección de profesión u oficio consagrado en el art. 35.1 de nuestra Constitución y directamente entroncado con el principio general pro libertate, consagrado en el art. 1.1. de nuestra Carta Magna. Este principio, tal y como ha señalado la STC 83/1984, de 24 de julio «autoriza a los ciudadanos a llevar a cabo todas aquellas actividades que la ley no prohíba o cuyo ejercicio no subordina a requisitos o condiciones determinadas». También debo señalar que las profesiones son susceptibles de clasificarse en libres, es decir, no se exige ninguna cualificación formal y titulada, dicho de otro modo, aquellas cuyo ejercicio está legalmente subordinado a la posesión de títulos concretos. El concepto constitucional de profesión titulada queda, circunscrito a aquella profesión "para cuyo ejercicio se requiere poseer estudios universitarios acreditados por la obtención del correspondiente título oficial» (STG 111/1993, de 25 de marzo), es decir, sólo la pueden ejercer quienes están en posesión de concretos títulos académicos (STC 83/1984), o, lo que es lo mismo, a «la posesión de estudios superiores, ratificados por el oportuno certificado, diploma o licencia (STC 42/1986, de 10 de abril $)^{24}$.

Tal y como advirtió el $\mathrm{TS}^{25}$ y con posterioridad el $\mathrm{TC}^{26}$, es necesario distinguir entre la regulación de la profesión sanitaria y la regulación del centro o establecimiento o la clasificación de los mismos que en su caso pudiera esta-

${ }^{24}$ Vide Miguel HERRERO de MIÑÓN y Juan FERNÁNDEZ del VALLADO, Especialización y profesión médica. La garantía constitucional de las profesiones tituladas y la especialización médica según la jurisprudencia, Cívitas, Madrid, 1997, pp. 25 y 26.

${ }^{25}$ Vide STS de 10 de abril de 1990 (Ar. 3638).

26 Vide STC 158/1992, de 28 de mayo: «[...]. Todos los argumentos avanzados por la parte recurrente se apoyan en una identificación entre el ejercicio de la profesión farmacéutica y el establecimiento de oficinas de farmacia que no es aceptable. Los farmacéuticos pueden ejercer su profesión de modos distintos a la dispensación al público de medicamentos de uso humano; y también pueden dedicarse a esta última clase de actividad en los servicios de farmacia de los hospitales, de los centros de salud, y de otros establecimientos legalmente autorizados para ello, de acuerdo con la Ley General de Sanidad de 1986 y la Ley del Medicamento de 1990. Cuestión distinta es que las oficinas de farmacia, junto con los servicios que se incardinan en las estructuras asistenciales mencionadas antes, ostenten el monopolio legal para custodiar, conservar y dispensar medicamentos; y también, que exista una íntima relación entre la titularidad de una oficina de farmacia y el ejercicio por cuenta propia de la profesión, en su vertiente de venta al público de productos medicinales, cimentado en que sólo los farmacéuticos pueden ser propietarios de oficinas de farmacia. Pero el que, de acuerdo con la legislación vigente en España, los farmacéuticos deseen establecerse por su cuenta para dispensar medicamentos al público deban adquirir una farmacia, o abrir una nueva, no permite confundir su derecho a ejercer la profesión, que les otorga su título profesional y les reconoce con carácter general el artículo 88 de la Ley General de Sanidad, con el derecho que ha sido objeto del litigio ante los Tribunales contencioso-administrativos, y del que dimana el presente recurso de amparo: el derecho a abrir una oficina de farmacia». 
blecerse. Respecto a la regulación de la profesión sanitaria, debemos remitirnos al artículo 36 GE, Ley de Colegios Profesionales, y a la regulación autonómica de aquellas Comunidades Autónomas con competencia exclusiva en materia de Colegios profesionales y ejercicio de profesiones tituladas, conforme a la legislación general ${ }^{27}$, modulada en la STC 3/2013, de 17 de enero, F.J. Octavo:

«[...]. La colegiación obligatoria para el ejercicio de determinadas profesiones constituye, en definitiva, un límite que se impone al contenido primario del derecho del art. 35.1 CE por ser un requisito necesario para su ejercicio, es también como acabamos de señalar, un límite esencial en la medida en que su exigencia supone la excepción, para quienes eligen una determinada profesión, del derecho fundamental de asociación en su vertiente negativa y, finalmente, resulta imprescindible pues, no se garantizaría el ejercicio del derecho del art. 35.1 CE en condiciones de igualdad, si el resultado del juicio que necesariamente debe realizarse a la vista de los concretos intereses públicos que concurren en cada caso, en cada profesión, y la obligación de elegir la alternativa menos gravosa entre las permitidas en el art. $36 \mathrm{CE}$, fuera distinta dependiendo del lugar de establecimiento o de prestación.

En conclusión, el inciso impugnado, al eximir de la colegiación obligatoria a los empleados públicos cuando ejercen la profesión por cuenta de la Administración, establece una excepción no contemplada en la Ley estatal de Colegios Profesionales, tal y como se razonó en el Fundamento Jurídico 6 de esta resolución. Siendo competente el Estado para establecer la colegiación obligatoria, lo es también para establecer las excepciones que afectan a los empleados públicos a la vista de los concretos intereses generales que pueden verse afectados, motivo por el cual debemos declarar que el inciso impugnado ha vulnerado las competencias estatales y, por tanto, su inconstitucionalidad».

27 Vide STS de 18 de octubre de 1989 (Ar. 7411), F.D.: «Tercero. [...]. La libertad de ejercicio de la profesión como derecho constitucional consagrado vincula a todos los poderes públicos (art. 9.1) y es un precepto directamente aplicable (art. 53.1) como, por otra parte tiene reconocido nuestro Tribunal Constitucional en todas las sentencias que ha dictado hasta el momento. [...]. Pero es que, además el derecho a la libertad de ejercicio profesional de los médicos-facultativos está perfectamente reglamentado en la Ley General de la Seguridad Social, y en otras disposiciones como ahora se dirá. 
Es necesario señalar que la igualdad en el ejercicio de la profesión ${ }^{28}$ debe ser considerada desde la doble óptica: activa (igualdad de prestación del ejercicio profesional frente a los ciudadanos) y pasiva del ejercicio profesional (igualdad de los profesionales). Así se indica en el fundamento $4^{\circ}$ de la STS de 21 de septiembre de 1999, ponente: Xiol Ríos:

«En principio el carácter ligado al ámbito o repercusión nacional parece que puede ser proyectado sobre aquellos aspectos en los que concurren especiales exigencias de igualdad entre todos los profesionales que ejerzan en España una determinada profesión, por lo que debe dirigirse en primer término la mirada sobre aspectos generales de organización, regulación y deontología profesional en los que pueda apreciarse tal aspecto pasivo o de igualdad de trato de los profesionales, como en el aspecto activo o de igualdad de prestación del ejercicio profesional frente a los ciudadanos a los que se refiera».

El RD 1277/2003, establece en su exposición de motivos que «la finalidad de este real decreto es regular las bases del procedimiento de autorización de centros, servicios y establecimientos sanitarios, establecer una clasificación, denominación y definición común para todos ellos, y crear un Registro y un Catálogo General», en desarrollo de lo previsto en los arts. 29.1 y 2 y 40.9 de la Ley 14/1986, de 25 de abril, General de Sanidad y el art. 26.2 de la Ley 16/2003, de 28 de mayo, de cohesión y calidad del Sistema Nacional de Salud. Se indica que las clasificaciones, denominaciones y definiciones contenidas en esta disposición constituyen los criterios generales para proceder, en desa-

Cuarto. Una manifestación de la libertad de ejercicio profesional es, en el ámbito de la libertad de los médicos, el de prescripción. Si hemos dicho que como tal derecho está consagrado en la Constitución, siendo de aplicación directa, sin necesidad de norma legal que lo desarrolle o perfeccione, como tal derecho igualmente está reconocido en la Ley General de la Seguridad Social. Así, el artículo 106 de la misma, que establece que "los facultativos encargados de los servicios sanitarios de este régimen general podrán prescribir libremente las fórmulas magistrales y las especialidades farmacéuticas reconocidas por la legislación sanitaria vigente que sean convenientes para la recuperación de la salud de sus pacientes. [...].

Séptimo. Por último, debe subrayarse que una cosa es controlar e inspeccionar la labor del médico de la Seguridad Social y otra muy distinta es ordenar como debe ejercer el médico su profesión al valorar si ha prescrito de forma idónea. Porque la idoneidad o no del médico para prescribir, diagnosticar o fijar el tratamiento del enfermo, constituye una esfera del contenido esencial de su derecho a ejercer libremente la profesión, en la que no puede entrar la Administración por la vía de dictar actos, resoluciones, circulares o instrucciones».

${ }^{28}$ Vide STS de 25 de junio de 2001 (Ar. 8749), F.D. Quinto y Séptimo, donde se desarrolla el contenido del principio general de unidad de la profesión médica. 
rrollo del art. 27.3 de la Ley 16/2003, a la determinación, con carácter básico, de las garantías mínimas y comunes de seguridad y calidad exigibles por las Comunidades Autónomas para autorizar la apertura y puesta en funcionamiento de los centros, servicios y establecimientos sanitarios, y añade, que no tiene el propósito de ordenar las profesiones sanitarias, ni limitar las actividades de los profesionales, sino sentar las bases para las garantías de seguridad y calidad de la atención sanitaria, previsión que se plasma en el art. 1.4 cuando señala que las disposiciones de este real decreto serán de aplicación sin perjuicio de las funciones y competencias profesionales que para el ejercicio de las profesiones sanitarias y la realización de las actividades profesionales correspondientes vengan establecidas por la normativa vigente.

Y todo ello en un contexto de progresiva consideración de la multidisciplinariedad de los equipos profesionales en la atención sanitaria, como uno de los principios del ejercicio de las profesiones sanitarias tal y como determina la Ley 44/2003, art. 4.7.e). Es más, el art. 9, contempla el trabajo en equipo, señalando que la atención sanitaria integral supone la cooperación multidisciplinaria, la integración de los procesos y la continuidad asistencial, y evita el fraccionamiento y la simple superposición entre procesos asistenciales atendidos por distintos titulados o especialistas, contemplando también en el art. 10 la gestión clínica de las organizaciones sanitarias, considerando como funciones de gestión clínica, entre otras, las relativas a la jefatura o coordinación de unidades y equipos sanitarios y asistenciales ${ }^{29}$.

Pero, en modo alguno el Real Decreto 1277/2003, de 10 de octubre o las disposiciones autonómicas sobre el particular, pueden introducir en la oferta asistencial de los centros sanitarios unidades asistenciales bajo la responsabilidad de personas con titulación oficial o habilitación profesional que, aun cuando no tengan la consideración legal de profesiones sanitarias tituladas y reguladas, en el sentido previsto en el art. 2.1 de la Ley 44/2003, lleven a cabo actividades sanitarias vinculadas con el bienestar y salud de las personas en centros que tengan la consideración de sanitarios. Así lo ha establecido la SAN de 26 de septiembre de 2007 (Ar. 664), al enjuiciar la Orden SGO/174/2006, de 29 de mayo, por la que se modifican los anexos del RD. 1277/2003, de 10 de octubre, y entendiendo que vulnera parcialmente el principio de legalidad, y

${ }^{29}$ Vide STS de 5 de julio de 2005, FD TERCERO: «Este carácter de la unidad de Nutrición y Dietética supone, de una parte, que el contenido funcional de la unidad asistencial que se encarga de su prestación no puede identificarse con las funciones específicas de una única profesión y especialidad sanitaria y que, como consecuencia, la unidad ha de dotarse con profesionales pertenecientes a las distintas profesiones sanitarias conformando un equipo multidisciplinar». 
por tanto, decreta su nulidad ${ }^{30}$, y la STS de 19 de julio de 2007 (Ar. 6882) al determinar «[...], el Decreto 252/2000 de la Junta de Galicia ni ha regulado una profesión, ni menos ha determinado cuando una profesión debe pasar a ser profesión titulada, sino que se ha limitado a establecer las condiciones y requisitos para el funcionamiento de un laboratorio de análisis clínicos, sin incidir además para nada en la posibilidad de que los Biólogos puedan o no realizar análisis clínicos» ${ }^{31}$.

\section{LA RAZÓN DE INTERÉS GENERAL EN EL DERECHO DE LA UNIÓN EUROPEA [SENTENGIA DEL TRIBUNAL DE JUSTICIA DE LAS COMUNIDADES EUROPEAS (GRAN SA- LA) DE 10 DE MARZO DE 2009]}

\section{Status quaestionis.}

La asistencia sanitaria es una necesidad central y básica de todos los ciudadanos de la Unión Europea. Sin una asistencia sanitaria satisfactoria, las libertades fundamentales dentro de la Unión pueden verse rápidamente restringidas. Los sistemas sanitarios deben hacer frente a un constante aumento de la demanda de prestaciones, responder a necesidades sanitarias cambiantes y estar preparados para crisis mayores de salud pública. Y todo ello en un contexto de expectativas que presuponen una alta calidad de las prestaciones sanitarias. Se trata de un sector económico que utiliza mucha mano de obra, que proporciona uno de cada diez empleos de la masa laboral europea y destina un promedio del $70 \%$ de los gastos sanitarios a salarios y remuneraciones.

30 Vide STS de 2 de febrero de 2010 (Ar. 3219), FD CUARTO: «En consecuencia este motivo de casación debe ser desestimado pues dentro del concepto de "profesiones sanitarias tituladas" de la Ley 44/2003, no comprende a los licenciados en Psicología dentro de la especialidad de Psicología Clínica». Vide Ley 33/2011, de 4 de octubre, General de Salud Pública (BOE de 5 de octubre), Disposición Adicional séptima, que regula la psicología en el ámbito sanitario (psicólogo general sanitario).

31 Vide STS de 14 de mayo de 2007 (Ar. 5849), FD NOVENO: «Tampoco es cierto que la aceptación de lo regulado en la Unidad Asistencial 101 suponga quebrar el principio de autorización administrativa y convierta en meramente discrecional la habilitación para el ejercicio de las llamadas "terapias no convencionales". Lo que el apartado correspondiente supone no es otra cosa que la consideración del ejercicio terapéutico por medios no convencionales (acupuntura, homeopatía y similares), atribuyendo a un profesional licenciado en medicina la responsabilidad de la corrección del tratamiento empleado, sin alterar ni suponer titulaciones o capacidades para el ejercicio de esa terapia no convencional, ni trazar pautas para su ejercicio». 
La Unión Europea tiene una gran preocupación por el personal y la carga de trabajo en el sector sanitario. El Dictamen del Comité Económico y Social Europeo sobre el «Libro Verde sobre el persona sanitario Europeo» [COM (2008) 725 final] (2009/C 317/20), lo explicita ${ }^{32}$.

El Libro Verde se concentra en los ámbitos clave: cambio demográfico, capacidades del sector sanitario, formación, gestión de la movilidad y fuga de cerebros de la UE, migración mundial del personal médico, datos de que se dispone como base para la adopción de decisiones, introducción y difusión de nuevas tecnologías para el aumento de la eficiencia y mejora de la calidad asistencial, refuerzo del principio de trabajo por cuenta propia, política de cohesión.

El principio de primacía del derecho comunitario se materializa en el respeto de los derechos y libertades que lo presiden. Una muestra del contexto en el que se debate el sector, lo constituye la sentencia del Tribunal de Justicia de las Comunidades Europeas (Gran Sala) de 10 de marzo de 2009 (TJCE/2009/50).

32 Vide Dictamen del Comité Económico y Social Europeo sobre el «Libro Verde sobre el personal sanitario europeo» $[\mathrm{COM}(2008) 725$ final], Conclusiones y recomendaciones del Comité:

«El CESE considera que se deben adoptar medidas que hagan atractivas para los jóvenes las profesiones sanitarias, con el fin de que aumente el número de vocaciones hacia ellas.

El CESE recomienda que se creen suficientes capacidades de personal sanitario, para hacer frente a las necesidades de atención y reforzar la capacidad de cribado, promoción de la salud y prevención de enfermedades.

La emigración indeseada de personal sanitario hacia otros países puede contrarrestarse también, a juicio del CESE, aumentando los salarios y mejorando las condiciones laborales, en su caso con nuevas responsabilidades. Nuevas responsabilidades suponen cualificaciones acorde con ellas, algo que, en líneas generales, aumentaría también el atractivo del sector. [...].

El CESE destaca el importante papel de las profesiones liberales en el sector sanitario, junto al núcleo central de este sector, constituido por los hospitales y los servicios públicos de salud, porque es especialmente gracias a ellas como se puede garantizar en condiciones de competencia y seguridad la relación asistencial o de tratamiento. Los profesionales liberales del sector sanitario han recibido una formación altamente cualificada gracias al esfuerzo de la sociedad civil de los Estados miembros a favor de la enseñanza pública. Los miembros del CESE, que representan esta sociedad civil, contemplan con preocupación el deseo de la Comisión de fomentar que el personal sanitario oriente el ejercicio de su actividad como profesión liberal. Al mismo tiempo, el CESE manifiesta su preocupación por la tendencia creciente al ejercicio de la falsa actividad por cuenta propia allí donde, por el tipo de actividad ejercido, resulta problemática (por ejemplo, en la asistencia a los enfermos y personas mayores)». 


\section{Litigios principales y cuestiones prejudiciales.}

Mediante decisión de 29 de agosto de 2001, se denegó la solicitud de autorización para abrir un centro sanitario privado consistente en una policlínica dental, en el distrito 21 de Viena, presentada por una sociedad con domicilio en Alemania. El órgano administrativo se basó en un determinado precepto legal (art. 4 de la Wr. KAG) y en un informe emitido por un experto de la Administración en materia médica. Según dicho informe, «los servicios odontológicos estaban suficientemente cubiertos en Viena por los centros sanitarios públicos, los centros privados de utilidad pública y los demás médicos concertados que ofrecen servicios comparables». Se había hecho esta apreciación sobre la base de la relación entre el número de habitantes y el número de profesionales de la odontología, el cual era de 2.207 habitantes por cada profesional. Por tanto, la apertura de este nuevo centro, no produciría el efecto de acelerar, intensificar o mejorar de forma sustancial los cuidados médicos en materia dental de los pacientes domiciliados en Viena y, en consecuencia, no existía ninguna necesidad que justificara tal apertura.

Por razones análogas, mediante decisión de 20 de septiembre de 2006, se denegó la solicitud de autorización presentada por la misma entidad mercantil para abrir una policlínica dental en Wels. Se efectuó el examen de dicha solicitud sobre la base del tiempo de espera comprobado para obtener una cita con los prestadores existentes, incluidos aquellos servicios de asistencia ambulatoria de los centros sanitarios.

La sociedad peticionaria interpuso un recurso contra cada una de dichas decisiones ${ }^{33}$, se decidió la acumulación de ambos procedimientos, y el órgano jurisdiccional se plantea un interrogante sobre la compatibilidad de las normas

33 Vide Sentencia del Tribunal de Justicia de las Comunidades Europeas (Gran Sala) de 10 de marzo de 2009, apartados: «23. En la vista el Gobierno austriaco cuestionó la admisibilidad de la petición de decisión prejudicial sosteniendo que Hartlauer (la mercantil solicitante) se fundó de una manera abusiva en las normas de Derecho comunitario. Señaló que, en el presente asunto, el vínculo transfronterizo fue en efecto establecido artificialmente ya que, según parece, Hartlauer es la filial de una sociedad austriaca que, según alegó, tiene la intención de establecerse nuevamente en Austria y que constituyó dicha filial con la única finalidad de hacer que su situación estuviera comprendida en el ámbito de aplicación del Derecho comunitario.

24. A este respecto, es preciso recordar que corresponde exclusivamente a los órganos jurisdiccionales nacionales que conocen del litigio y que han de asumir la responsabilidad de la decisión judicial que debe adoptarse apreciar, a la luz de las peculiaridades de cada asunto, tanto la necesidad de una decisión prejudicial para poder dictar sentencia, como la pertinencia de las cuestiones que plantean al Tribunal de Justicia. Por consiguiente, cuando las cuestiones planteadas se refieren a la integración del Derecho comunitario, el Tribunal de Justicia está, en principio obligado a pronunciarse [...]. 
nacionales controvertidas en el asunto principal relativas a la definición de las necesidades en materia de apertura de centros sanitarios, con el art. $43^{34} \mathrm{CE}$, así como sobre la influencia en dicha compatibilidad de la circunstancia de que, en la apreciación de tales necesidades, se tenga en consideración la asistencia ofrecida por los servicios de atención ambulatoria de determinados centros sanitarios, lo cual, en principio, tiene por efecto hacer aún más dificil el acceso de un nuevo candidato al mercado de referencia.

Las cuestiones prejudiciales planteadas al Tribunal de Justicia, son las siguientes:

«1) ¿Se opone el artículo 43 CE (en relación con el artículo $48^{35}$ CE) a la aplicación de una norma nacional, en virtud de la cual para la apertura de un centro sanitario privado consistente en una policlínica dental autónoma (policlínica dental) es necesaria una autorización, la cual debe ser denegada cuando, teniendo en cuenta el objeto del centro indicado en la solicitud y los servicios que se prevé que preste, a la luz de la atención que ya prestan los médicos concertados que ejercen libremente su profesión, las instalaciones pertenecientes a las cajas de enfermedad y las instalaciones concertadas, así como los "Dentisten" concertados, no existe ninguna necesidad de abrir esa policlínica dental?

25. El Tribunal de Justicia no puede negarse a pronunciarse sobre una cuestión prejudicial planteada por un órgano jurisdiccional nacional más que cuando resulta evidente que la interpretación o la apreciación de la validez de una norma de Derecho comunitario, solicitadas por el órgano jurisdiccional nacional, no tienen relación alguna con la realidad o con el objeto del litigio principal o cuando el problema es de naturaleza hipotética $[\ldots] »$.

${ }^{34}$ Vide Tratado de Funcionamiento de la Unión Europea, art. 49 (antiguo artículo 43 TCE): «En el marco de las disposiciones siguientes, quedarán prohibidas las restricciones a la libertad de establecimiento de los nacionales de un Estado miembro en el territorio de otro Estado miembro. Dicha prohibición se extenderá igualmente a las restricciones relativas a la apertura de agencias, sucursales o filiales por los nacionales de un Estado miembro establecidos en el territorio de otro Estado miembro.

La libertad de establecimiento comprenderá el acceso a las actividades no asalariadas y su ejercicio, así como la constitución y gestión de empresas y, especialmente, de sociedades, tal como se definen en el párrafo segundo del artículo 54, en las condiciones fijadas por la legislación del país de establecimiento para sus propios nacionales, sin perjuicio de las disposiciones del capítulo relativo a los capitales».

${ }^{35}$ Vide Tratado de Funcionamiento de la Unión Europea, art. 54 (antiguo artículo 48 TCE): «Las sociedades constituidas de conformidad con la legislación de un Estado miembro y cuya sede social, administración central o centro de actividad principal se encuentre dentro de la Unión quedarán equiparadas, a efectos de aplicación de las disposiciones del presente capítulo, a las personas físicas nacionales de los Estados miembros.

Por sociedades se entiende las sociedades de Derecho civil o mercantil, incluso las sociedades cooperativas, y las demás personas jurídicas de Derecho público o privado, con excepción de las que no persigan un fin lucrativo». 
2) ¿influye de alguna manera en la respuesta a la primera cuestión el hecho de que la comprobación de la necesidad deba, además, tomar en consideración la asistencia ofrecida por los servicios de atención ambulatoria de los centros sanitarios públicos, de los centros privados de utilidad pública y de los demás centros sanitarios concertados?».

\section{Petición de autorización de un centro o establecimiento sani- tario y libre prestación de servicios.}

3.1. Un supuesto de interés: sentencia del Tribunal de Justicia (Gran Sala) de 1 de junio de 2010.

La Comisión Europea, en su afán liberalizador puso en práctica la Directiva 2006/123/CE del Parlamento Europeo y del Consejo, de 12 de diciembre de 2006, relativa a los servicios en el mercado interior (DOUE n ${ }^{\circ}$ L 376, de 27 de diciembre de 2006), denominada coloquialmente Directiva Bolkestein (hace referencia al entonces comisario encargado del mercado interior europeo $)^{36}$. Su transposición al derecho español se ha realizado a través de la Ley 17/2009, de 23 de noviembre, sobre el libre acceso a las actividades de servicios y su ejercicio, a través de diversas normas estatales y autonómicas, dentro de las que destaco la Ley 25/2009, de 22 de diciembre, de modificación de diversas leyes para su adaptación a la Ley sobre el libre acceso a las actividades de servicios y su ejercicio (Ley ómnibus).

La propia Directiva, en el apartado 2, establece la consecución de los siguientes objetivos:

36 Vide José Antonio RAZQUIN LIZARRAGA, "De la intervención administrativa previa al control a posteriori: la reforma del procedimiento administrativo común a consecuencia de la Directiva de Servicios", Revista Aranzadi Doctrinal, 2, (2010), pp. 2-3, donde resume los propósitos de la Directiva de Servicios en torno a tres pilares fundamentales: «En primer lugar, la regla general de limitación de la intervención administrativa previa ensamblada con el principio de proporcionalidad. Se pretende la drástica restricción del régimen de autorizaciones, pues sólo se admite de forma excepcional cuando sea indispensable debiendo superar, previa evaluación, el triple test de no discriminación, necesidad justificada por una razón imperiosa de interés general y proporcionalidad. En segundo lugar, los procedimientos autorizados deben ser predeterminados, adecuados, objetivos y no excesivamente onerosos. Y en tercer lugar, se fijan criterios de autorización que determinan la potestad de otorgamiento para evitar su ejercicio arbitrario y las autorizaciones tienen alcance nacional e indefinido y están sujetas en caso de restricción a exigencias de publicidad y concurrencia, con una lista negra de requisitos prohibidos y una lista gris de requisitos por evaluar para verificar su compatibilidad con las condiciones de no discriminación, necesidad y proporcionalidad». 
«Un desarrollo armonioso, equilibrado y sostenible de las actividades económicas en el conjunto de la Comunidad, un alto nivel de empleo y de protección social, la igualdad entre el hombre y la mujer, un crecimiento sostenible y no inflacionista, un alto grado de competitividad y de convergencia de los resultados económicos, un alto nivel de protección y de mejora de la calidad de vida, la cohesión económica y social y la solidaridad entre los Estados miembros» ${ }^{37}$.

La Directiva 2006/123/CE del Parlamento Europeo y del Consejo de 12 de diciembre de 2006, relativa a los servicios en el mercado interior, art. 14, y la Ley 17/2009, de 23 de noviembre, art. 10, establece:

«En ningún caso se supeditará el acceso a una actividad de servicios en España o su ejercicio al cumplimiento de lo siguiente: a) Requisitos discriminatorios basados directa o indirectamente en la nacionalidad, incluido que el establecimiento se encuentre o no en el territorio de la autoridad competente, o el domicilio social; y en particular: requisito de nacionalidad o de residencia para el prestador, su personal, los partícipes en el capital social o los miembros de los órganos de gestión y supervisión; b) Prohibición de estar establecido en varios Estados miembros o de estar inscrito en los registros o colegios o asociaciones profesionales de varios Estados miembros; c) Limitaciones de la libertad del prestador para elegir entre un establecimiento principal o secundario y, especialmente, la obligación de que el prestador tenga su establecimiento principal en el territorio español, o limitaciones de la libertad de elección entre establecimiento en forma de sucursal o de filial; d) Condiciones de reciprocidad con otro Estado miembro en el que el prestador tenga ya su establecimiento, con excepción de las previstas en los instrumentos comunitarios en materia de energía; e) Requisitos de naturaleza económica que supedite la concesión de la autorización a la prueba de la existencia de una necesidad económica o de una demanda en el mercado, que se evalúen los efectos económicos, posibles o reales, de la actividad a que se haga una apreciación de si la actividad se ajusta a los objetivos de programación económica fijados por la autoridad competente o a que se comercialicen productos o servicios de un tipo o precedencia determinada. Las razones imperiosas de interés general que se invoquen no podrán encubrir requi-

37 Vide: Julio V. GONZÁLEZ GARCÍA, "Autorizaciones, comunicaciones previas y declaraciones responsable en la transposición de la Directiva de Servicios", Revista d'estudis autonómics i federals, 11, (2010), p. 261; Magdalena M. MARTÍN MARTÍNEZ, "En busca de la Europa social: reflexiones críticas sobre la calidad de los servicios en la Directiva Bolkestein", Revista de Derecho de la Unión Europea, 14, (2008), p.137; Helena VILLAREJO GALENDE, "La simplificación administrativa en la Directiva de Servicios en el mercado interior", Revista de Derecho de la Unión Europea, 14, (2008), pp. 47-82. 
sitos de planificación económica; f) Intervención directa o indirecta de competidores, incluso dentro de órganos consultivos, en la concesión de autorizaciones o en la adopción de otras decisiones de las autoridades competentes relativas al establecimiento para el ejercicio de una actividad de servicios, sin perjuicio de la actuación de colegios profesionales y consejos generales y autonómicos de colegios profesionales, como autoridades competentes, en el ámbito de las competencias que les otorga la Ley. Esta prohibición se extiende a organismos como las cámaras de comercio y a los interlocutores sociales en lo que concierne al otorgamiento de autorizaciones individuales, pero esa prohibición no afectará a la consulta de organismos como las cámaras de comercio o de los interlocutores sociales sobre asuntos distintos a las solicitudes de autorización individuales, ni a una consulta del público en general; g) Obligación de que la constitución de garantías financieras o la suscripción de un seguro deban realizarse con un prestador u organismo establecido en el territorio español; g) Obligación de haber estado inscrito con carácter previo durante un período determinado en los registros de prestadores existentes en el territorio español o de haber ejercido previamente la actividad durante un período determinado en dicho territorio».

No debemos olvidar la importancia de los servicios en el seno de la Unión Europea y en el ámbito español, pues tal y como determina el Preámbulo de la Ley 17/2009, de 23 de noviembre, sobre el libre acceso a las actividades de servicios y su ejercicio (BOE de 24 de noviembre, núm. 283), es: «el sector más importante, tanto de la economía europea como de la española, en términos económicos y de empleo y el que ha experimentado un mayor desarrollo en los últimos años».

Pero, esta disposición no puede aplicarse al ámbito de los servicios sanitarios. Su preámbulo, considerando 22, determina: «La exclusión de los servicios sanitarios del ámbito de aplicación de la presente Directiva debe abarcar los servicios sanitarios y farmacéuticos prestados por profesionales de la salud a los pacientes con objeto de evaluar, mantener o restaurar su estado de salud cuando estas actividades están reservadas a profesiones reguladas en el Estado miembro en que se preste el servicio». El art. 2.2.f) de la Directiva excluye «los servicios sanitarios, prestados o no en establecimientos sanitarios, independientemente de su modo de organización y de financiación a escala nacional y de su carácter público o privado».

Sin embargo, su art. 15, exige a los Estados miembros un examen de la existencia de trabas específicas: límites cuantitativos y territoriales y, concretamente, límites fijados en función de la población o de una distancia geográfica mínima entre prestadores. 
En este contexto, la Comisión Europea ha propugnado una política liberalizadora, por ejemplo en materia de establecimiento de farmacias ${ }^{38}$, que se ha materializado en la incoación de distintos procedimientos por incumplimientos abiertos contra varios Estados miembros:

«En los últimos tres años los esfuerzos por liberalizar lo más posible el sector de las oficinas de farmacia se han concretado en varios procedimientos administrativos por incumplimiento, algunos de los cuales han acabado ante el Tribunal de Justicia. Se trata de una estrategia que la Comisión Europea ha desarrollado hasta 2008, cuando mostraba su intención de continuar los procedimientos por incumplimiento a través de la Dirección General de Mercado Interior y Servicios en distintos ámbitos del mercado interior, citando expresamente los relativos a la movilidad de los pacientes y el reembolso de los costes médicos, el establecimiento de farmacias, etc. Al mismo tiempo la Comisión Europea se ha propuesto perseguir las violaciones más groseras del art. 43 del Tratado CE, que consagra el derecho de establecimiento, y del art. 49 del Tratado CE, relativo a la libre prestación de servicios, en relación con los servicios de salud y lo que la Comisión denomina "las discriminaciones patentes en el sector de las farmacias"»" 39 .

Estos Estados han sido: Italia ${ }^{40}$, Austria $^{41}$, Alemania $^{42}$, Portugal ${ }^{43}$ y España ${ }^{44}$. En ningún caso se ha decretado por la jurisprudencia que el régimen jurídico vigente fuese contrario al Derecho comunitario ${ }^{45}$.

38 Vide Juan Francisco PÉREZ GÁLVEZ, "Ordenación farmacéutica y libertad de establecimiento en la Unión Europea", Noticias de la Unión Europea, 321, (2011), pp. 117-136. Vide Juan Francisco PÉREZ GÁLVEZ, "Reconocimiento del título de farmacéutico especialista en la Unión Europea: farmacia hospitalaria [Comentario a la STJCE (Sala 2ª ) de 8 de mayo de 2008]", Noticias de la Unión Europea, 306, (2010), pp. $105-117$.

39 Vide David ORDOÑEZ SOLÍS, "La regulación española de las oficinas de farmacia en el contexto del mercado único a la luz de la jurisprudencia europea", Gaceta furídica de la Unión Europea y de la Competencia, 10, (2009), p. 19.

40 Vide Comisión Europea, IP/06/858, Bruselas, 28 de junio de 2006. El procedimiento por incumplimiento lo interpuso la Comisión Europea ante el Tribunal de Justicia el 22 de diciembre de 2006. A juicio de la Comisión las normas italianas relativas a las farmacias son incompatibles con la libertad de establecimiento (art. $43 \mathrm{CE}$ ) y la libre circulación de capitales (art. $56 \mathrm{CE}$ ). Vide Sentencia del Tribunal de Justicia de las Comunidades Europeas (Gran Sala) de 19 de mayo de 2009.

41 Vide Comisión Europea, IP/06/858, Bruselas, 28 de junio de 2006. En términos similares al caso de Italia, la Comisión Europea adoptó en junio de 2006 un dictamen motivado contra Austria al apreciar la incompatibilidad de las restricciones legislativas relativas a las farmacias con la libertad de establecimiento garantizada por el art. 43 del Tratado CE. 
Ante esta situación, la Sentencia del Tribunal de Justicia (Gran Sala) de 1 de junio de 2010 determinó que los riesgos para la salud pública y el equilibrio financiero de los sistemas de seguridad social ${ }^{46}$, permiten a los Estados de la Unión Europea imponer serias restricciones a la comercialización de medicamentos.

En los últimos años se han planteado dos interrogantes fundamentales. Primero, si la reserva de su venta al por menor, en principio, exclusivamente a los farmacéuticos, debido a las garantías que éstos deben presentar y a la información que deben ser capaces de proporcionar al consumidor, vulnera o no el derecho comunitario. La Sentencia del Tribunal de Justicia de las Comunidades Europeas (Gran Sala) de 19 de mayo de 2009, entiende que no, y por tanto reserva la titularidad y la explotación de las farmacias exclusivamente a quienes tengan la condición de farmacéutico, sin que exista vulneración del derecho de establecimiento, ni de la libre circulación de capitales.

42 Vide Comisión Europea, IP/08/1352, Bruselas, 18 de septiembre de 2008. En este caso, en septiembre de 2008, seguía en la fase administrativa del procedimiento por incumplimiento y la Comisión Europea ya había emitido su dictamen motivado en el que cuestionaba la conformidad con el Derecho comunitario del régimen de propiedad de las farmacias. A juicio de la Comisión, Alemania debe derogar la prohibición para los no farmacéuticos de poseer una farmacia y la prohibición dirigida a los farmacéuticos de poseer más de cuatro farmacias (una principal y tres sucursales). Asimismo, la Comisión Europea impugna ante el Tribunal de Justicia la legislación alemana que impone una proximidad entre la farmacia principal y sus sucursales. Se trata de medidas incompatibles con la libertad de establecimiento y no pueden ser justificadas por razones vinculadas a la protección de la salud.

43 Vide Comisión Europea, IP/08/1352, Bruselas, 18 de septiembre de 2008. Para la Comisión Europea no es admisible desde el punto de vista del Derecho comunitario que la legislación portuguesa prohíba a las empresas comercializadoras de medicamentos poseer o gestionar farmacias; asimismo, la legislación portuguesa prohíbe la posesión de más de cuatro farmacias. Se trata, a juicio de la comisión Europea, de exigencias desproporcionadas respecto de la necesidad de garantizar la protección de la salud y tampoco son compatibles con la libertad de establecimiento.

${ }^{44}$ Vide Comisión Europea, IP/06/858, Bruselas, 28 de junio de 2006. La Comisión Europea hace girar su dictamen motivado en torno al carácter restrictivo de la normativa de planificación territorial y a la prohibición de la acumulación de farmacias.

${ }^{45}$ Vide José Antonio RAZQUIN LIZARRAGA, "La reserva de la propiedad y la titulariza de las oficinas de farmacia a los farmacéuticos no es contraria al Derecho comunitario europeo", Actualidad Jurídica Aranzadi, 777, (2009), pp. 7-11.

46 Vide Antonio EZQUERRA HUERVA, "Acerca del blindaje comunitario de la reserva de la propiedad de las oficinas de farmacia a favor de los farmacéuticos [Consideraciones al hilo de las sentencias del Tribunal de Justicia de las Comunidades Europeas de 19 de mayo de 2009 (asuntos acumulados C171/07 y C-172/07, y asunto C-531/06)]”, Revista de Administración Pública, 180, (2009), pp. 268-271: «La desafortunada vinculación entre el régimen de titularidad de las farmacias y el coste público de la prestación farmacéutica».

Revista Andaluza de Administración Pública

ISSN: 0034-7639, núm. 84, Sevilla, septiembre-diciembre (2012), págs. 41-88 
El segundo interrogante, cuestionaba la existencia de un modelo que limita el número de autorizaciones (ordenación farmacéutica), y que por tanto puede vulnerar la libertad de establecimiento en base a criterios demográficos o geográficos, o que diseña modalidades de adjudicación con una baremación de méritos cuestionable, en base al régimen jurídico de la Unión europea. La Sentencia del Tribunal de Justicia (Gran Sala) de 1 de junio de 2010, se ha pronunciado sobre el particular, resolviendo las dos cuestiones prejudiciales planteadas por el Tribunal Superior de Justicia de Asturias.

Respecto de la primera, ha determinado, que, «no puede considerarse que la normativa controvertida en los litigios principales vaya más allá de lo necesario para lograr el objetivo perseguido» ${ }^{47}$, y por tanto concluye declarando en el fallo, que «el artículo 49 TFUE debe interpretarse en el sentido de que no se opone, en principio, a una normativa nacional, como la controvertida, que impone límites a la concesión de autorizaciones de establecimiento de nuevas farmacias», en virtud de los módulos poblacionales y distancias mínimas expuestos. Esta es la primera conclusión que declara el fallo de la sentencia.

En relación con la segunda cuestión prejudicial planteada, el Tribunal falla que «el artículo 49 TFUE, en relación con el artículo 1, apartados 1 y 2, de la Directiva 85/432/CEE del Consejo, de 16 de septiembre de 1985, relativa a la coordinación de las disposiciones legales, reglamentarias y administrativas para ciertas actividades farmacéuticas, y el artículo 45, apartado 2, letras e) y g), de la Directiva 2005/36/CE del Parlamento Europeo y del Consejo, de 7 de septiembre de 2005, relativa al reconocimiento de cualificaciones profesionales, debe interpretarse en el sentido de que se opone a criterios (desigualdad de trato, privilegiar en el proceso de selección a los farmacéuticos autóctonos) como los recogidos en los puntos 6 y 7, letra c), del anexo del Decreto 72/2001, de 19 de julio, regulador de las oficinas de farmacia y botiquines en el Principado de Asturias, en virtud de los cuales se selecciona a los titulares de nuevas farmacias».

De este modo se cierra el círculo abierto en el año 2006 por la Comisión Europea. Los Estados de la Unión, en el ámbito de la salud pública, disponen de una esfera competencial infranqueable para las instituciones comunitarias, y por tanto, pueden ordenar y organizar sus servicios sanitarios -ordenación farmacéutica-, de la forma que estimen más conveniente. Ningún acto de aplicación de las libertades fundamentales establece normas de acceso a las actividades del ámbito farmacéutico destinadas a establecer las condiciones en las

${ }^{47}$ Vide STJUE (Gran Sala) de 1 de junio de 2010, apartado 112. 
que se pueden crear nuevas farmacias en el territorio de los estados miembros. De este modo se permite la existencia de un régimen de liberalización o de normas más o menos restrictivas en los distintos países.

La distribución competencial española entre el Estado y las Comunidades Autónomas, permite a éstas disponer la regulación del acceso, explotación y transmisión de unos establecimientos -las farmacias- sanitarios y mercantiles. En todo caso, deben respetar el Derecho de la Unión imposibilitando la discriminación por razón de nacionalidad o por condicionantes que tienen que ver con el desarrollo del ejercicio profesional en una determinada zona geográfica, y haciendo posible el acceso y la promoción o mejora de los farmacéuticos titulados.

Desde el punto de vista formal, la argumentación es impecable. Desde el punto de vista material, es posible cuestionar un modelo seguro y fiable, en la medida en que las restricciones impuestas casan mal con el imparable proceso de liberalización que afecta a todos los ámbitos de la vida de los ciudadanos europeos.

El modelo español puede modificarse. A corto plazo es difícil (la presión corporativa es extraordinaria), pero no existen problemas de fondo que imposibiliten un mayor y mejor acceso de los ciudadanos a esta prestación. El modelo comunitario, sustentado en el principio de subsidiariedad, concluye remitiendo a los operadores nacionales (ejecutivo, legislativo y judicial) la responsabilidad de una actividad, que de una u otra forma, seguirá estando en el punto de mira ${ }^{48}$. El legislador, contando con los actores principales, tiene la última palabra.

\subsection{Autorización condicionada a la prestación ofrecida por los medios concertados.}

En la sentencia del Tribunal de Justicia de las Comunidades Europeas (Gran Sala) de 10 de marzo de 2009, el órgano jurisdiccional remitente pide,

48 Vide David ORDÓÑEZ SOLÍS, "La regulación española de las oficinas de farmacia en el contexto del mercado único a la luz de la jurisprudencia europea", Gaceta furídica de la Unión Europea y de la Competencia, 10, (2009), p. 30: «En suma y aun cuando los vientos de liberalización de y desregulación no soplen ahora con el brío de antes del inicio de la crisis económica, los intereses de unos y de otros, de gran trascendencia económica y social, harán que el sector farmacéutico y el régimen de las oficinas de farmacia esté en el punto de mira. Ahora bien, dentro del marco comunitario europeo y respetando los límites del Derecho de la Unión, corresponde a las autoridades nacionales - en España al legislador estatal y a los legisladores autonómicos- establecer finalmente el modelo de oficina de farmacia que nuestra sociedad requiere». 
esencialmente, que se dilucide si los artículos 43 y 48 CE se oponen a unas disposiciones nacionales, como las controvertidas en el litigio principal, en virtud de las cuales es necesaria una autorización para abrir un centro sanitario privado consistente en una policlínica dental autónoma y por las que debe denegarse dicha autorización cuando, teniendo en cuenta la asistencia ya ofrecida por los médicos concertados, no exista necesidad alguna de abrir esa policlínica.

El Tribunal de Justicia ya ha declarado que cuando una normativa nacional sujete el desarrollo de una actividad a un requisito relacionado con las necesidades económicas o sociales de esa actividad, constituye una restricción dado que limita el número de prestadores de servicios ${ }^{49}$. En el supuesto que estoy estudiando, la normativa nacional supedita la apertura de un centro sanitario, a la expedición de una autorización administrativa previa. Establece, además, que esta autorización sólo puede concederse si "existe una necesidad" que justifique la apertura, a la luz de la asistencia que ya ofrecen, en particular, los médicos concertados. Esta normativa desanima a las empresas de otros Estados, e incluso les impide desarrollar sus actividades. Por tanto, parece claro que esta normativa constituye una restricción a la libertad de establecimiento en el sentido del artículo $43 \mathrm{CE}$, a pesar de la supuesta inexistencia de discriminación por razón de nacionalidad de los profesionales interesados.

Los gobiernos austriaco y noruego sostienen que la exigencia de autorización previa para la apertura de una policlínica dental autónoma está justificada por razones relacionadas con la protección de la salud pública. Alegan que dicho régimen garantiza un servicio médico de calidad, equilibrado y accesible a todos, y asegura el equilibrio financiero de la seguridad social por cuanto permite a los organismos de la misma controlar los gastos ajustándolos a las necesidades planificadas. Tal exigencia es indispensable para preservar las bases del sistema establecido por el legislador austriaco, el cual ha optado por dar prioridad a un sistema de prestaciones en especie, así como a los cuidados médicos de la población mediante estructuras financiadas con fondos públicos. Por tanto, los servicios de asistencia deben ser prestados principalmente por los médicos concertados. Si se permite la extensión incontrolada de la oferta mediante la creación de nuevas policlínicas dentales autónomas tendría consecuencias nefastas sobre la situación económica de dichos médicos y, también sobre el ac-

${ }^{49}$ Vide: Sentencia del Tribunal de Justicia de las Comunidades Europeas de 27 de septiembre de 2001 (TJCE 2001, 252), apartado 59 y Sentencia del Tribunal de Justicia de las Comunidades Europeas de 15 de junio de 2006 (TJCE 2006, 170), apartado 29. 
ceso de los pacientes a los servicios médicos prestados por tales profesionales en el conjunto del territorio nacional, toda vez que, en cierta medida, las referidas policlínicas desalojarían a estos últimos del mercado.

El gobierno austriaco alega igualmente «que dichas limitaciones se imponen debido a que, en el sector de la salud pública, las Leyes que regulan ordinariamente el mercado sólo se aplican de forma muy limitada y que son frecuentes los defectos del mercado. Puntualiza que dicho sector no se rige concretamente por la Ley de la oferta y de la demanda. Sostiene que la demanda es inducida por la oferta, de modo que un incremento de la oferta no implica una reducción de los precios, ni tampoco el reparto de un mismo volumen de prestaciones entre varios prestadores, sino un incremento del volumen de las prestaciones a precios constantes. Infiere que, por lo tanto, un aumento incontrolado del número de prestadores de servicios médicos impone cargas incontrolables en los organismos de seguridad social. Alegan que, no obstante, éstos no tienen ninguna posibilidad de promover una acción reguladora mediante una política de concertación, habida cuenta de que, aunque no propongan a los nuevos prestadores la forma de un convenio, están obligados a desembolsar, en el marco del sistema de reembolso de las cantidades anticipadas por el asegurado, sumas sensiblemente idénticas a las pagadas en el marco del sistema de prestaciones en especie. A su juicio, de ello resulta que de manera inmediata se pone en peligro la capacidad financiera del sistema de seguridad social.

A este respecto, debe recordarse que una restricción a la libertad de establecimiento, que es aplicable sin discriminación por razón de nacionalidad, puede estar justificada por razones imperiosas de interés general, siempre que sea adecuada para garantizar la realización del objetivo que persigue y no vaya más allá de lo que es necesario para alcanzar dicho objetivo» ${ }^{50}$.

Si no hay discriminación de nacionalidad, y la protección de la salud pública figura entre las razones de interés general que, en virtud del art. $46^{51} \mathrm{CE}$,

50 Vide Sentencia del Tribunal de Justicia de las Comunidades Europeas (Gran Sala) de 10 de marzo de 2009, apartados 43 y 44.

51 Vide Tratado de Funcionamiento de la Unión Europea, art. 52 (antiguo artículo 46 TCE): «1. Las disposiciones del presente capítulo (Capítulo II: Derecho de establecimiento) y las medidas adoptadas en virtud de las mismas no prejuzgarán la aplicabilidad de las disposiciones legales, reglamentarias y administrativas que prevean un régimen especial para los extranjeros y que estén justificadas por razones de orden público, seguridad y salud públicas.

2. El Parlamento Europeo y el Consejo, con arreglo al procedimiento legislativo ordinario, adoptarán directivas para la coordinación de las mencionadas disposiciones». 
apartado 1, pueden justificar restricciones a la libertad de establecimiento, con esta medida se busca propiciar dos objetivos, a saber: contribuir a la consecución de un elevado grado de protección de la salud manteniendo un servicio médico y hospitalario de calidad, equilibrado y accesible a todos; se previene un perjuicio grave para el equilibrio financiero del sistema de seguridad social.

Pero, el sistema planteado quiebra por dos motivos. En primer lugar, porque a diferencia de lo que ocurre con las nuevas policlínicas dentales, no somete el establecimiento de los consultorios de grupo a un régimen de autorización previa. En segundo lugar, porque un régimen de autorización previa no puede legitimar un comportamiento discrecional de las autoridades nacionales que pueda privar de su eficacia a las disposiciones de Derecho comunitario, en particular, a las relativas a una libertad fundamental. El sistema debe basarse en criterios objetivos, conocidos de antemano, que garanticen su adecuación para establecer suficientemente los límites del ejercicio de la facultad de apreciación de las autoridades.

De este modo responde el Tribunal a la primera cuestión planteada, no siendo necesario en virtud de su contenido, responder a la segunda.

En todo caso, debo concluir esta colaboración manifestando la notable disparidad existente entre los sistemas de salud de los países de la Unión. La libertad de circulación de profesionales y el establecimiento de centros, servicios y establecimientos sanitarios, no es posible, alegando razones de interés general cuestionadas y cuestionables. Las restricciones son admisibles -según la doctrina jurisprudencial europea- en el ámbito de las oficinas de farmacia, y se mantiene una posición antagónica en centros como los que han sido objeto de análisis en la sentencia del Tribunal de Justicia de las Comunidades Europeas (Gran Sala) de 10 de marzo de 2009.

Además de buenas palabras, necesitamos hechos. La consecución de la homogeneidad formal y material, están todavía lejos de ser alcanzadas. Queda mucho camino por recorrer. 